\title{
Application of a GC-ECD for measurements of biosphere-atmosphere exchange fluxes of peroxyacetyl nitrate using the relaxed eddy accumulation and gradient method
}

\author{
A. Moravek ${ }^{1}$, T. Foken ${ }^{2,3}$, and I. Trebs ${ }^{1, *}$ \\ ${ }^{1}$ Max Planck Institute for Chemistry, Biogeochemistry Department, P.O. Box 3060, 55020 Mainz, Germany \\ ${ }^{2}$ Department of Micrometeorology, University of Bayreuth, Universitätsstr. 30, 95447 Bayreuth, Germany \\ ${ }^{3}$ Bayreuth Center of Ecology and Environmental Research (BayCEER), University of Bayreuth, Bayreuth, Germany \\ "now at: Centre de Recherche Public - Gabriel Lippmann, Department Environment and Agro-Biotechnologies, \\ 41 rue du Brill, 4422 Belvaux, Luxembourg
}

Correspondence to: A. Moravek (a.moravek@mpic.de)

Received: 13 January 2014 - Published in Atmos. Meas. Tech. Discuss.: 26 February 2014

Revised: 16 June 2014 - Accepted: 17 June 2014 - Published: 10 July 2014

\begin{abstract}
Peroxyacetyl nitrate (PAN) may constitute a significant fraction of reactive nitrogen in the atmosphere. Current knowledge about the biosphere-atmosphere exchange of PAN is limited, and only few studies have investigated the deposition of PAN to terrestrial ecosystems. We developed a flux measurement system for the determination of biosphere-atmosphere exchange fluxes of PAN using both the hyperbolic relaxed eddy accumulation (HREA) method and the modified Bowen ratio (MBR) method. The system consists of a modified, commercially available gas chromatograph with electron capture detection (GC-ECD, Meteorologie Consult GmbH, Germany). Sampling was performed by trapping PAN onto two pre-concentration columns; during HREA operation one was used for updraft and one for downdraft events, and during MBR operation the two columns allowed simultaneous sampling at two measurement heights. The performance of the PAN flux measurement system was tested at a natural grassland site, using fast-response ozone $\left(\mathrm{O}_{3}\right)$ measurements as a proxy for both methods. The measured PAN fluxes were comparatively small (daytime PAN deposition was on average $-0.07 \mathrm{nmol} \mathrm{m}^{-2} \mathrm{~s}^{-1}$ ) and, thus, prone to significant uncertainties. A major challenge in the design of the system was the resolution of the small PAN mixing ratio differences. Consequently, the study focuses on the performance of the analytical unit and a detailed analysis of errors contributing to the overall uncertainty. The error of the PAN mixing ratio differences ranged from 4 to $15 \mathrm{ppt}$
\end{abstract}

during the MBR and between 18 and 26 ppt during the HREA operation, while during daytime measured PAN mixing ratios were of similar magnitude. Choosing optimal settings for both the MBR and HREA method, the study shows that the HREA method did not have a significant advantage towards the MBR method under well-mixed conditions as was expected.

\section{Introduction}

Peroxyacetyl nitrate $\left(\mathrm{PAN}, \mathrm{CH}_{3} \mathrm{C}(\mathrm{O}) \mathrm{O}_{2} \mathrm{NO}_{2}\right.$ ) is an important organic nitrogen compound, whose production is often associated with the anthropogenic emissions of $\mathrm{NO}_{\mathrm{x}}(=\mathrm{NO}$ $+\mathrm{NO}_{2}$ ) and non-methane hydrocarbons (NMHC) (Stephens, 1969). It is formed through the oxidation of the peroxyacetyl radical $(\mathrm{PA})$ with nitrogen dioxide $\left(\mathrm{NO}_{2}\right)$ :

$\mathrm{CH}_{3} \mathrm{C}(\mathrm{O}) \mathrm{O}_{2}+\mathrm{NO}_{2}+M \rightleftharpoons \mathrm{CH}_{3} \mathrm{C}(\mathrm{O}) \mathrm{O}_{2} \mathrm{NO}_{2}+M$.

The decomposition of PAN is dependent on temperature (back reaction of R1) and also on the reaction of PA with nitrogen monoxide (NO):

$\mathrm{CH}_{3} \mathrm{C}(\mathrm{O}) \mathrm{O}_{2}+\mathrm{NO} \rightarrow \mathrm{CH}_{3} \mathrm{C}(\mathrm{O}) \mathrm{O}+\mathrm{NO}_{2}$. 
Due to its long lifetime at low temperatures PAN can be transported in the upper troposphere over long distances and acts as a reservoir species for $\mathrm{NO}_{\mathrm{x}}$. In this way, PAN can alter the ozone $\left(\mathrm{O}_{3}\right)$ budget and the oxidative capacity of the atmosphere, especially in unpolluted and $\mathrm{NO}_{\mathrm{x}}$-poor environments (Singh and Hanst, 1981). In addition, the dry deposition of PAN is a source of nitrogen for remote, nutrient-poor ecosystems and, hence, influences carbon sequestration (Magnani et al., 2007).

Besides thermal decomposition, dry deposition is the major removal mechanism of PAN from the atmosphere (Shepson et al., 1992; Hill, 1971; Garland and Penkett, 1976). However, only very few studies have directly measured the flux of PAN to terrestrial ecosystems (Wolfe et al., 2009; Schrimpf et al., 1996; Doskey et al., 2004; Turnipseed et al., 2006). The results of these and other indirect studies about PAN deposition fluxes show a large range in the magnitude of PAN fluxes and deposition velocities. The latter varies from around $0 \mathrm{~cm} \mathrm{~s}^{-1}$ to $1.5 \mathrm{~cm} \mathrm{~s}^{-1}$ for different ecosystem types. Although the difference in the obtained results might be caused by environmental conditions and different uptake mechanisms of plant species, they can also be attributed to relatively large uncertainties in the determined PAN fluxes. Both Turnipseed et al. (2006) and Wolfe et al. (2009) used a chemical ionisation mass spectrometer (CIMS) and applied the eddy covariance technique (EC) above a pine forest canopy; they found flux uncertainties of $25-65 \%$ and $40 \%$, respectively. Doskey et al. (2004) applied the modified Bowen ratio (MBR) method using a gas chromatograph with electron capture detection (GC-ECD) and determined uncertainties of PAN deposition velocities of 45 to $450 \%$ during daytime above a grassland ecosystem. These uncertainties are mainly caused by the low precision and accuracy of the concentration measurement, which therefore represents a major challenge in flux measurements of PAN. For instance, Wolfe et al. (2009) report total uncertainty for a single point PAN measurement of $\pm(21 \%+3 \mathrm{ppt})$, employing a CIMS at a pine forest site. Recent measurements with GCECD achieved a precision $(1 \sigma)$ of 1 to $3 \%$ (Fischer et al., 2011; Zhang et al., 2012; Mills et al., 2007), while the accuracy is typically below $10 \%$ (e.g. Flocke et al., 2005; Fischer et al., 2011). Schrimpf et al. (1996) derived PAN fluxes from measurements of PAN and ${ }^{222} \mathrm{Rn}$ concentration gradients only at night-time when concentration differences were large enough to be resolved by the analysing unit. Other existing studies inferred PAN fluxes using indirect methods such as boundary layer budget models (Garland and Penkett, 1976; Shepson et al., 1992) or chamber studies on leaves (Sparks et al., 2003; Teklemariam and Sparks, 2004). Mostly, these are also prone to large uncertainties, as either they rely on rough assumptions or the errors were not derived under field conditions. Hence, our current understanding of the controlling mechanisms and the importance of PAN deposition for the atmospheric and biogeochemical nitrogen cycles is still very limited. Although PAN and other organic nitrates may constitute more than $50 \%$ of $\mathrm{NO}_{\mathrm{y}}$ (total odd nitrogen compounds), the deposition fluxes of these species as part of the nitrogen cycle are largely unknown (Neff et al., 2002).

We developed a flux measurement system using a GCECD for the determination of biosphere-atmosphere exchange fluxes of PAN. The system can be operated to apply both the MBR and the hyperbolic relaxed eddy accumulation (HREA) method. Both methods are favourable when no fastresponse gas analyser for the application of the EC method is available. They represent less expensive techniques, potentially applicable also for long-term PAN flux measurements. Particularly at low atmospheric mixing ratios of PAN, a longer integration time or a trapping mechanism is required to resolve very small mixing ratio differences required for flux measurements.

In this study we describe the setup of the PAN flux measurement system and its application on a natural grassland site using $\mathrm{O}_{3}$ as a proxy scalar. We present a detailed assessment of the system requirements to resolve the expected PAN fluxes at the site. We additionally evaluate the applicability of HREA and MBR under various environmental conditions. An extensive quality control (detailed systematic and random error analysis) is performed, allowing the investigation of the system performance in relation to the magnitude of the determined PAN fluxes. We find that HREA and MBR are generally applicable to determine PAN fluxes using our GC-ECD setup, but the limitation of the analytical unit to precisely resolve mixing ratio differences remains a major drawback.

\section{Methods}

\subsection{Flux measurement techniques}

\subsubsection{Hyperbolic relaxed eddy accumulation (HREA)}

Relaxed eddy accumulation (REA) systems are widely used to determine biosphere-atmosphere exchange fluxes of trace gases, in cases when high-frequency measurements for the application of the EC method are not possible. According to Businger and Oncley $(1990)$ the turbulent flux $\left(F_{\mathrm{REA}}\right)$ is determined by the difference of two reservoir mixing ratios $(\Delta \chi)$, multiplied by a proportionality factor $b$, the standard deviation of the vertical wind speed $\left(\sigma_{\mathrm{w}}\right)$ and the molar density of air $\rho_{\mathrm{m}}$ (conversion of mixing ratio to molar concentration):

$F_{\mathrm{REA}}=b \cdot \sigma_{\mathrm{w}} \cdot \rho_{\mathrm{m}} \cdot\left(\chi_{\mathrm{w}+}-\chi_{\mathrm{w}-}\right)=b \cdot \sigma_{\mathrm{w}} \cdot \rho_{\mathrm{m}} \cdot \Delta \chi$.

Equation (1) implies that sampled air must be separated into two reservoirs, one for updraft and one for downdraft events during a certain sampling period (typically $30 \mathrm{~min}$ ). The separation is made with a fast switching valve, which is controlled according to the sign of the vertical wind speed $(w)$ measured by a 3-D sonic anemometer. The $b$ value is determined using a proxy scalar $\left(\chi_{\text {proxy }}\right)$, which can be measured with high frequency: 
$b=\frac{F_{\text {proxy }}}{\sigma_{\mathrm{w}} \cdot \rho_{\mathrm{m}} \cdot\left(\bar{\chi}_{\text {proxy }}^{+}-\bar{\chi}_{\text {proxy }}^{-}\right)}$.

For an ideal Gaussian frequency distribution the $b$ value is 0.627 (Wyngaard and Moeng, 1992). However, experimental data show that it varies and is on average slightly lower (Baker, 2000). While some studies found the $b$ value to be independent of stability (Businger and Oncley, 1990; Foken et al., 1995), a slight stability dependence was reported by Ammann and Meixner (2002). In addition, the $b$ value may also vary for different scalars.

Besides the appropriate timing of the valve switching and the choice of the proxy scalar, a major challenge for the application of the REA technique is small values of $\Delta \chi$, which must be resolved by the chemical analysis. The value of $\Delta \chi$ can be increased by the application of a so-called dead band, a threshold below which air samples are discarded when $w$ is close to zero. The most significant increase of $\Delta \chi$ is retrieved with the HREA method (Bowling et al., 1999), which was used in our experiment (Sect. 2.4) since values of $\Delta \chi_{\text {PAN }}$ near the precision of the chemical analysis were expected (see Sect. 3.1). The HREA method defines a threshold $H$ according to the flux of a proxy scalar as

$H \geq\left|\frac{w^{\prime} \cdot \chi_{\text {proxy }}^{\prime}}{\sigma_{\mathrm{w}} \cdot \sigma_{\chi_{\text {proxy }}}}\right|$,

where $w^{\prime}$ and $\chi_{\text {proxy }}^{\prime}$ are the Reynolds fluctuation of $w$ and $\chi_{\text {proxy }}$, respectively, and $\sigma_{\chi_{\text {proxy }}}$ is the standard deviation of the proxy scalar. If scalar similarity between the scalar of interest and the proxy exists, $\Delta \chi$ is maximised since the threshold is only exceeded when high vertical wind speed fluctuations are accompanied by high fluctuations of the proxy scalar.

REA systems are usually designed for inert scalar quantities since air samples are stored in the reservoirs. However, the lifetime of PAN in the troposphere varies significantly, mainly with temperature and the $\mathrm{NO} / \mathrm{NO}_{2}$ ratio (e.g. at $30^{\circ} \mathrm{C}$ and a $\mathrm{NO} / \mathrm{NO}_{2}$ ratio of 0.5 the lifetime of PAN is about $45 \mathrm{~min}$ ). Hence, its reactivity is a critical point in the design of a REA system for PAN.

\subsubsection{Modified Bowen ratio method (MBR)}

Gradient methods based on the flux-gradient relationship are commonly used for the determination of biosphereatmosphere exchange fluxes. The MBR method assumes that the ratio between the molar flux $\left(F, F_{\text {proxy }}\right)$, in this case normalised by $\rho_{\mathrm{m}}$, and the mixing ratio difference $(\Delta \chi$, $\left.\Delta \chi_{\text {proxy }}\right)$ of two measurement heights is equal for the scalar of interest and a proxy scalar (Businger, 1986; Liu and Foken, 2001). This implies that both quantities would be transported with the same transfer velocity $\left(v_{\text {tr }}\right)$ :
$v_{\mathrm{tr}}=-\frac{F}{\rho_{\mathrm{m}} \cdot \Delta \chi}=-\frac{F_{\text {proxy }}}{\rho_{\mathrm{m}} \cdot \Delta \chi_{\text {proxy }}}$.

If $F_{\text {proxy }}$ is determined by eddy covariance, the trace gas flux can be calculated as

$F=-v_{\text {tr }} \cdot \rho_{\mathrm{m}} \cdot \Delta \chi=F_{\text {proxy }} \cdot \frac{\Delta \chi}{\Delta \chi_{\text {proxy }}}$.

It is important to note that for the MBR method $\Delta \chi$ is defined as the mixing ratio difference from the upper minus the lower height $\left(\Delta \chi=\chi\left(z_{2}\right)-\chi\left(z_{1}\right)\right)$, which yields, for the same sign of $F$, the opposite sign of $\Delta \chi$ to that with the REA method. Furthermore, when using mixing ratios instead of concentrations, differences in the molar air density between the two measurement heights are assumed to be negligible.

A major prerequisite for the application of the MBR method is the scalar similarity of the scalar of interest and the proxy scalar. Furthermore, the occurrence of internal boundary layers and chemical transformations within the considered layer violate the application of the gradient approach in general. If the two heights are sampled subsequently and not simultaneously, non-stationarities of the scalar mixing ratios within the sample interval (typically $30 \mathrm{~min}$ ) are a source of uncertainty, especially for systems with a low temporal resolution.

Like for the HREA method, the major challenge for the successful application of the MBR method for PAN is the accurate determination of small values of $\Delta \chi$ by the chemical analysis. Especially during daytime, when the boundary layer is well mixed, $\Delta \chi$ values are expected to be small. For conditions with weak developed turbulence, the transfer velocities determined with the MBR method are expected to be very small and prone to large uncertainties. Hence, Liu and Foken (2001) suggest omitting flux data where the friction velocity $\left(u_{*}\right)$ is very low $\left(u_{*}<0.07 \mathrm{~m} \mathrm{~s}^{-1}\right)$, which mainly concerns night-time periods.

\subsection{Modification of the PAN GC-ECD}

We used a commercially available GC-ECD for PAN (Meteorologie Consult $\mathrm{GmbH}$, Germany), which is a further development of the system described by Volz-Thomas et al. (2002). To prevent contamination of the main column, the automatic GC-ECD contains a pre-column, which is backflushed once all substances of interest have eluted onto the main column (Fig. 1). The chromatogram retrieved by the ECD is automatically integrated by the ADAM32 software program (Meteorologie Consult GmbH, Germany), which is installed on a PC and facilitates the control of the GC system, the data acquisition and reduction via a USB-based I/O module (USB-1408FS, Measurement Computing Corp., USA) (for details on GC-ECD analysis see the Supplement Sect. SM1). 


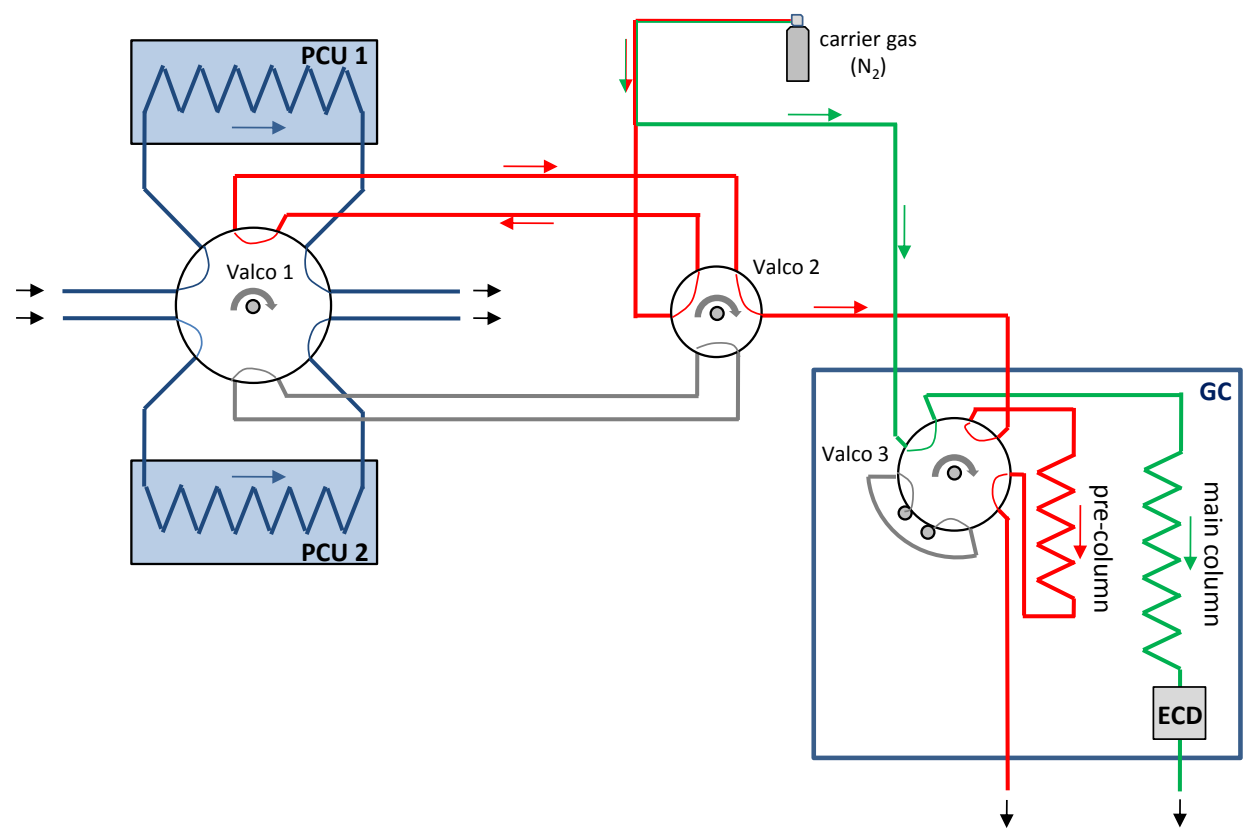

Figure 1. Simplified flow scheme of the modified GC-ECD for PAN flux measurements. During the sampling mode (shown in this example) the sample gas is drawn through two pre-concentration units (PCU 1, PCU 2). For the subsequent analysis a 12-port valve (Valco 1) is actuated, whereas a 6-port valve (Valco 2) switches between the two pre-concentration units (see text for further explanation). The analysis of PAN is performed by a commercially available GC-ECD (Meteorologie Consult GmbH, Germany).

We modified and optimised the GC-ECD for the application of both the HREA and MBR method to determine PAN fluxes. The two reservoirs required for the HREA sampling (see Sect. 2.1.1) can also be used for the simultaneous sampling at two heights and subsequent analysis by the GC-ECD required for the MBR method. Sampling for both methods was realised by trapping PAN onto two preconcentration capillary columns (MXT-1, Restek, USA; for details see Sect. SM1 in the Supplement) over the sampling period and subsequent analysis by the GC-ECD. For this, we modified commercially available pre-concentration units (Meteorologie Consult GmbH, Germany) and implemented them together with two additional multi-port valves (Valco, VICI, Switzerland) in an extended housing of the GC-ECD (Fig. 1). The modifications of the two pre-concentration units (PCU 1, PCU 2) mainly involved improvements on the temperature control and stability as well as a removable housing, which allowed us to exchange the columns easily for maintenance (for details see Sect. SM1 in the Supplement). All connections were made of $1 / 16$ in. OD (outside diameter) PEEK tubing (ID (inside diameter) 0.050 and $0.075 \mathrm{~mm}$ ), which was coated with silicon tubes as insulation against temperature changes. During the sampling mode, sample air was drawn through the pre-concentration columns, which were cooled to $-5^{\circ} \mathrm{C}$ to enhance the pre-concentration efficiency for PAN. The pre-concentration was performed in conservation mode (Novak et al., 1979); i.e. the frontal zone of PAN would not leave the pre-concentration column during the sampling period. Depending on the overall sampling time this required a low flow rate of only a few $\mathrm{mL} \mathrm{min}^{-1}$ (see Sects. 2.4 and 2.5 for details on flow rate and flow control). At the end of the sampling time, PAN was injected from PCU 1 into the separation columns by back-flushing the preconcentration units (Valco 1; see Fig. 1) and simultaneous heating of the MXT- 1 column to $25^{\circ} \mathrm{C}$ (see Sect. SM1 in the Supplement). PCU 2 was injected in the same way $10 \mathrm{~min}$ after the injection of PCU 1 by actuation of the 6-port valve (Valco 2; see Fig. 1). After a further 5 min, the system was switched back to sampling mode (Valco 1), which led to a total analysing time of $15 \mathrm{~min}$ for both PCUs. The in-built pneumatic-actuated 10-port valve (Valco 3; see Fig. 1) was kept from the commercial analyser to connect the pre- and main column in series just before the injection of both PCUs and to back-flush the pre-column 5 min after injection (in the case of PCU 1) or just before switching back to the sampling mode (in the case of PCU 2).

\subsection{Field experiment: experimental site and general setup}

The testing, validation and application of the PAN flux measurement system was carried out at a natural grassland site $\left(49.9685^{\circ} \mathrm{N}, 8.1481^{\circ} \mathrm{E}\right)$ at the estate of the Mainz-Finthen Airport, Rhineland-Palatinate, Germany. The vegetation is classified as a nutrient-poor steppe-like grassland ecosystem with a mean canopy height of $0.6 \mathrm{~m}$ and extends roughly over $0.7 \mathrm{~km} \times 1 \mathrm{~km}$, providing good fetch conditions for flux 
measurements. The modified GC-ECD was installed in an air-conditioned container, which was located about $20 \mathrm{~m}$ north of the eddy covariance complex, a compromise between short inlet tubing and a large distance to reduce flow distortion.

Three-dimensional wind vector and temperature were measured by a sonic anemometer (CSAT3, Campbell Scientific Inc., USA) at $3 \mathrm{ma.g.l}$. and recorded at $20 \mathrm{~Hz}$ using a data logger (CR3000, Campbell Scientific Inc., USA). In addition, a fast-response open-path $\mathrm{CO}_{2} / \mathrm{H}_{2} \mathrm{O}$ analyser (LI-7500A, LI-COR, USA) was installed next to the sonic anemometer and sampled by the logger at the same frequency (for details see Moravek et al., 2013). All turbulent fluxes and stability parameters were calculated using the eddy covariance software TK3.1 (Mauder and Foken, 2011).

We chose $\mathrm{O}_{3}$ as a proxy scalar for both HREA and the MBR method due to its similarity to PAN (see Sect. 4.3 for discussion). For this, a fast-response $\mathrm{O}_{3}$ detector (Enviscope $\mathrm{GmbH}$, Germany) was added to the eddy covariance complex. The sensor discs required for the fast-response $\mathrm{O}_{3}$ measurements were prepared according to Ermel et al. (2013) and exchanged every five to eight days. Since the sensitivity of the sensor disc typically decreases with time, the $\mathrm{O}_{3}$ signal was calibrated by independent $\mathrm{O}_{3}$ measurements at $4 \mathrm{~m}$ a.g.l. using a slow UV-absorption $\mathrm{O}_{3}$ analyser (49c, Thermo Environmental, USA). The employed analyser was part of a trace gas profile system with inlet heights at $0.2,0.8$ and $4 \mathrm{~m}$ a.g.l., with which also $\mathrm{NO}$ and $\mathrm{NO}_{2}$ were measured (CLD 780 TR, Eco-Physics, Switzerland). The profile system was installed on a profile mast located $3 \mathrm{~m}$ northwest of the eddy covariance complex.

For the application of the modified Bowen ratio technique, we modified a UV-absorption $\mathrm{O}_{3}$ analyser (49i, Thermo Environmental, USA) to directly measure mixing ratio differences between $0.8 \mathrm{~m}$ and $4 \mathrm{~m}$ a.g.l. (differential $\mathrm{O}_{3}$ measurements, see Cazorla and Brune, 2010). To account for systematic errors the instrument was zeroed every $30 \mathrm{~min}$ by directing the gas flow of each height through an ozone scrubber for $1.5 \mathrm{~min}$ before entering the absorption cells. The $\mathrm{O}_{3}$ analyser was placed in a waterproof box together with a data logger (CR1000, Campbell Scientific Inc., USA) for instrument control and data acquisition. For the inlet lines opaque $1 / 4$ in. OD PFA tubes and PTFE membrane particle filters (Pall Corporation, USA) were used.

The PAN flux measurement system was operated in the HREA mode in the period from 20 to 27 September 2011 and in the MBR mode from 19 August to 4 September 2011.

\subsection{Setup of PAN flux measurement system: HREA operation}

The inlet for the HREA system was installed at $3 \mathrm{ma}$ a.g.l. at the eddy covariance complex, with a horizontal displacement distance to the CSAT3 of $25 \mathrm{~cm}$. Since a long inlet line from the eddy covariance complex to the air-conditioned container (Sect. 2.3) and a low sample flow through the PCUs (Sect 2.2) were required, we designed a REA system with a bypass (see Moravek et al., 2013), where subsamples are drawn from the main sample line into the reservoirs (Fig. 2a).

For the main sample line a $21.5 \mathrm{~m}$ long opaque PFA tube with $1 / 4$ in. OD was used, equipped with a HDC-II particle filter (ACRO50 LCF, Pall Corporation, USA). This filter type did not cause an increasing pressure drop with time due to contamination, which is typically observed with PTFE membrane filters. The flow rate through the inlet tube was regulated by a mass flow controller (EL-flow, Bronkhorst HighTech, Netherlands) and set to a volume flow of $11 \mathrm{~L} \mathrm{~min}^{-1}$ to ensure turbulent flow conditions $(R e \sim 3800)$. A buffer volume was implemented upstream of the membrane pump (MD 8C, Vacuubrand GmbH, Germany) to ensure a constant performance of the mass flow controller. The volume flow instead of the mass flow was regulated to maintain a constant lag time between the change of sign of the vertical wind speed and the switching of the splitter valves (see Moravek et al., 2013). The lag time was calculated online by crosscorrelation between the vertical wind velocity and the highfrequency signal of an in-built high-frequency $\mathrm{CO}_{2}$ analyser, ranging between 1.3 and $1.7 \mathrm{~s}$, while the main variation was attributed to the sensor separation effect (see Moravek et al., 2013).

During sampling mode, the splitter valves were switched according to the sign of the vertical wind velocity (Fig. 2a). A third splitter valve was used for dead band situations. The splitter valves were mounted on a PFA manifold, which was installed in the main sample line. We used bi-stationary valves (type 6604, Bürkert, Germany) to reduce the heat development causing a reduction of PAN mixing ratios, which was observed when using other solenoid valves. In addition, the valves were composed of inert materials (PEEK, FFKM) and they feature a low internal volume $(35 \mu \mathrm{L})$. Tests with a fast pressure sensor revealed that the valves were suitable for a switching frequency of more than $33 \mathrm{~Hz}$ (see Sect. SM2 in the Supplement).

The subsamples, which were diverted by the splitter valves from the main sample line, were purged through $1 / 8 \mathrm{in}$. OD Nafion dryers (MD-50-12-F, Perma Pure LLC, USA) to prevent the condensation of water at $-5^{\circ} \mathrm{C}$ in the PCUs (Sect. 2.2). To improve the performance of the Nafion dryers, we introduced a by-pass system, which allowed purging the splitter valves and the Nafion dryers with $30 \mathrm{~mL} \mathrm{~min}^{-1}$ regulated by a mass flow controller (Fig. S4 in Sect. SM5 in the Supplement). The dew point of the sample air in the outflow of the Nafion dryers was constantly monitored with a humidity probe (HMP series, Vaisala, Finland, not shown in Fig. 2a). The average dew point was $-14^{\circ} \mathrm{C}$ and never exceeded $-10^{\circ} \mathrm{C}$ during the experiments. A loss of PAN by Nafion dryers was not observed. 


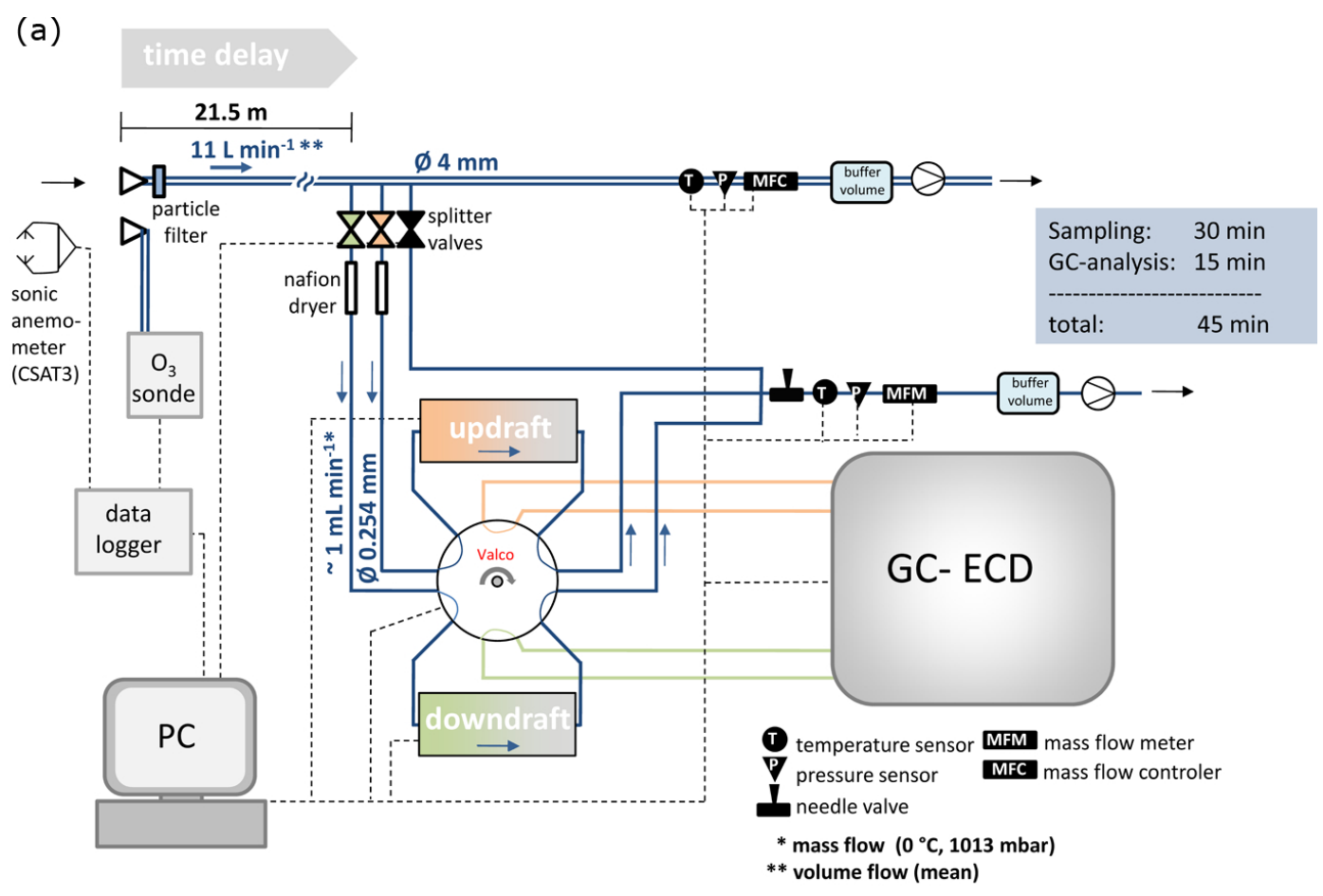

(b)

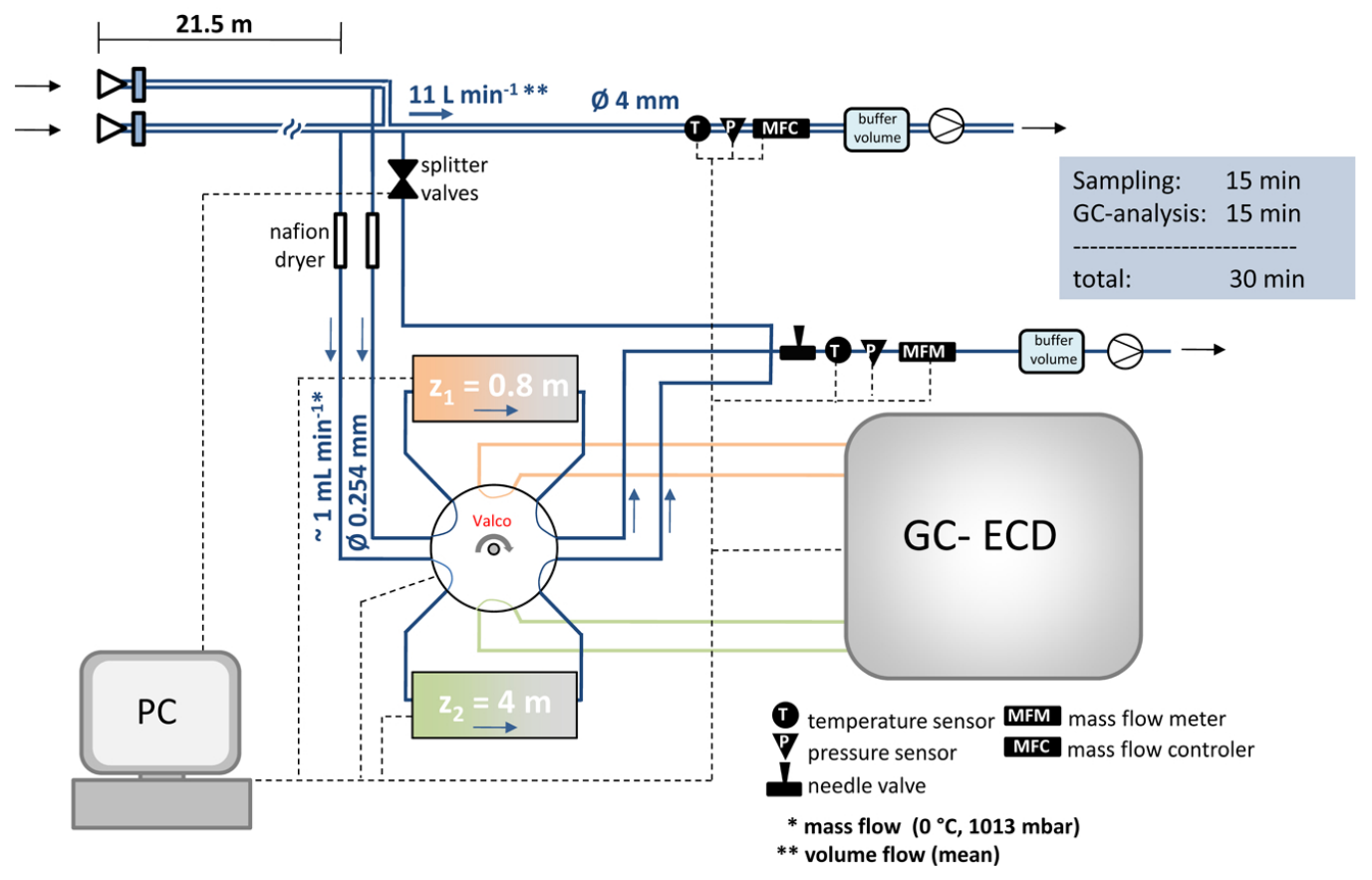

Figure 2. Setup of the PAN flux measurement system showing the inlet system, the pre-concentration units, the GC-ECD for PAN analysis, the data acquisition and control as well as additional measurements. (a) Operation in the HREA mode: the system contains one inlet line, and subsamples are drawn according to the sign of the vertical wind velocity into the PCUs acting as reservoirs. The hyperbolic dead band is calculated using the signal of a high-frequency $\mathrm{O}_{3}$ analyser. (b) Operation in MBR mode: two separate inlet lines are employed, and the system is capable of simultaneously sampling at two inlet heights and performing subsequent analysis of PAN. 
The sample air was drawn through the PCUs with a flow rate of $1 \mathrm{~mL} \mathrm{~min}^{-1}$ (STP), which was regulated with a needle valve (CNV1A150S1, VICI, Switzerland) and monitored with a mass flow meter (EL-flow, Bronkhorst High-Tech, Netherlands). A pressure sensor (HCX series, Sensortechnics $\mathrm{GmbH}$, Germany) and a temperature probe were installed upstream of the mass flow meter (Fig. 2a). A buffer volume was employed upstream of the sample pump (NMP 830 KNDC $\mathrm{B}$, KNF Neuberger GmbH, Germany) to exclude an effect of high-frequency variations in the pump performance on the flow rate through the PCUs.

During operation of the PAN flux measurement system in the HREA mode the sampling period was set to $30 \mathrm{~min}$. Together with the analysing time of 15 min (Sect. 2.2) a total time resolution of $45 \mathrm{~min}$ was achieved.

A PC together with a LabVIEW (National Instruments Corporation, USA) software program was used for the control of the HREA system. The software program was designed to perform (a) acquisition of all signals and control of mass flow controllers, (b) coordinate rotation of the wind vector using the double rotation method, (c) hyperbolic dead band calculation, (d) switching of splitter valves and (e) data storage with a frequency of $20 \mathrm{~Hz}$. Details on the accurate timing of the signal transmission and processing are given in Sect. SM2 in the Supplement. Statistical values used for the coordinate rotation and the calculation of the hyperbolic dead band were retrieved by applying a moving average window of $5 \mathrm{~min}$. Furthermore, the LabVIEW program calculated the online cross-correlation for the lag time for the switching of the splitter valves as well as the actual lag of the highfrequency $\mathrm{O}_{3}$ signal at the end of every sampling interval (i.e. every $45 \mathrm{~min}$ ) (see Moravek et al., 2013).

\subsection{Setup of PAN flux measurement system: MBR operation}

For the application of the MBR method, the setup of the GCECD, the flow control and data acquisition was the same as described in Sect. 2.4. However, the inlet system was modified for simultaneous sampling at two measurement heights (Fig. 2b). Two 1/4 in. OD PFA inlet tubes were installed at the profile mast, one at 0.8 and the other at $4.0 \mathrm{~m}$ a.g.l. Like for the HREA operation, the inlets were equipped with HDC-II particle filters and had a length of $21.5 \mathrm{~m}$. The combined volume flow rate at the position of the mass flow controller was set to $11 \mathrm{~L} \mathrm{~min}^{-1}$, leading to a residence time of $\sim 3$ s. Subsamples were drawn directly from the inlet tubes, through the Nafion dryers into the PCUs with a total flow rate of $2 \mathrm{~mL} \mathrm{~min}^{-1}$ (STP) (Fig. 2b). Since both sample lines and both PCUs were identical in their setup, it was assumed that the flow rate through each PCU was close to $1 \mathrm{~mL} \mathrm{~min}^{-1}$. The sampling time was reduced to $15 \mathrm{~min}$ to ensure that the frontal zone of PAN would not leave the pre-concentration column. With an analysing time of $15 \mathrm{~min}$ (Sect. 2.2) the total time resolution during the MBR operation was $30 \mathrm{~min}$.

\subsection{Calibration and quality control}

\subsubsection{Calibration method}

The flux measurement system was calibrated regularly to account for changes in the performance of the PCUs and the increasing sensitivity of the ECD with time. The PAN calibration air was produced using a photolytic calibration unit (Meteorologie Consult GmbH, Germany) as described by Pätz et al. (2002). Synthetic air (Air Liquide, Germany) was first enriched with acetone in a permeation cell. A known mixing ratio of NO standard gas (Air Liquide, Germany) was then photolysed in a reaction cell together with the acetone-air mixture to produce PAN. Finally, the calibration air was diluted with zero air that was produced from ambient air aspirated through a membrane pump (N035, KNF Neuberger GmbH, Germany) and purified with active charcoal and Purafil ${ }^{\circledR}$. To obtain the same flow and pressure conditions as during the sampling mode, we aspirated the diluted calibration air through an identical inlet system, consisting of one tube during the HREA operation and two tubes during the MBR operation.

Since the total mass collected by the PCUs varied during HREA sampling, PAN calibration coefficients $(m, c)$ were obtained by normalising the peak integrals (Int) with the sampled volume (vol), derived from the actual sampling time of each PCU and the flow rate (at STP) through the PCUs. The PAN mixing ratios $\left(\chi_{\mathrm{PAN}}\right)$ were then determined as

$\chi_{\mathrm{PAN}}=m \cdot \frac{\mathrm{Int}}{\mathrm{vol}}+c$

for both PCU 1 and PCU 2 individually.

To obtain a similar amount of sample volume to that during the HREA sampling, the splitter valves were switched according to the sign of the vertical wind velocity and with the respective dead band during the HREA calibration. Consequently, the pressure and flow conditions in the PCUs were the same as during sampling, which improved the accuracy of the calibration.

\subsubsection{Determination of PAN mixing ratio difference errors}

For both the HREA and the MBR method, the accuracy and precision of $\Delta \chi_{\text {PAN }}$ is of crucial importance. Uncertainties in $\Delta \chi_{\text {PAN }}$ may be caused for example by slight variations in the sample flow or in the pre-concentration efficiency of the two reservoirs. To account for these systematic and random errors of $\Delta \chi_{\text {PAN }}$, we performed side-by-side measurements of the two PCUs before, during and/or after the flux measurements (the periods are denoted as SBS_HREA 1, SBS_HREA 2, SBS_MBR 1 and SBS_MBR 2 and comprised for each method at least $50 \mathrm{~h}$ in total). Accordingly, we introduced an artificial time delay of $30 \mathrm{~s}$ for the switching of the splitter valves for the HREA operation. This ensured that 
the actual sampling time and the pressure conditions were identical with the HREA sampling. According to the parameterisation by Moravek et al. (2013), who describe the effect of an erroneous lag time on REA fluxes, the HREA flux is negligible for an artificial lag time of $30 \mathrm{~s}$ under most environmental conditions. However, a larger artificial time lag can be chosen in future experiments to avoid any potential contribution from lower frequencies. For the side-by-side measurements during the MBR operation, we placed the two trace gas inlets side by side at $0.8 \mathrm{~m}$ a.g.l. For both the HREA and the MBR method, systematic differences between the two reservoirs were corrected for by adjusting PCU 2 to PCU 1 using an orthogonal fit function. The random error (precision) of $\Delta \chi_{\text {PAN }}$ (denoted as $\sigma_{\triangle \mathrm{PAN}}$ ) was defined as the standard deviation of the residuals of the fit according to Wolff et al. (2010) (see Sect. 3.3).

\subsubsection{Random flux error, flux detection limit and quality control}

The random flux error $\left(\sigma_{F}\right)$ was deduced for both the HREA and the MBR method by combining the random errors of the individual terms in Eqs. (1) and (5), respectively, using Gaussian error propagation (see Sect. SM3 in the Supplement), while for the HREA method the $b$ value in Eq. (1) was substituted by Eq. (2). The required individual random errors were determined as follows. (a) The random error of the PAN mixing ratio differences $\left(\sigma_{\triangle \mathrm{PAN}}\right)$ was deduced from the sideby-side measurements (Sect. 2.6.2). (b) The random error of mixing ratio differences of the scalar proxy $\left(\sigma_{\Delta \mathrm{O}_{3}}\right)$ was derived for the HREA method from the calibration. A value of $1 \%$ was found and applied as a conservative estimate. For the MBR method, $\sigma_{\mathrm{AO}_{3}}$ was derived by propagating the standard deviations of the ambient air and zero air measurement of the differential $\mathrm{O}_{3}$ analyser (Sect. 2.3). (c) The random error of the $\mathrm{O}_{3}$ flux $\left(\sigma_{\mathrm{F}_{3}}\right)$ was calculated by the TK3.1 software program according to Mauder et al. (2013), representing the turbulence sampling error. Although it was not directly used for the flux calculation, we derived the random error of the $b$ value $\left(\sigma_{b}\right)$ by combing the individual random errors in Eq. (2) (see Sect. SM3 in the Supplement). For the determination of the random error of $\sigma_{\mathrm{w}}\left(\sigma_{\sigma_{\mathrm{w}}}\right)$, we assumed that $\sigma_{\sigma_{\mathrm{w}}}$ mainly results from the uncertainty of the vertical wind speed measurement, which is given by the manufacturer as $0.5 \mathrm{~mm} \mathrm{~s}^{-1}$ (see Sect. SM3 in the Supplement).

For all above-mentioned quantities, we define values to be insignificant from zero and, thus, below the detection limit when the relative random error (denoted as $\sigma_{x}^{\%}$ ) of the quantity $(x)$ exceeds $100 \%$. Additionally, PAN fluxes are regarded as below the flux detection limit when $\Delta \chi_{\mathrm{PAN}}$ is below the detection limit (i.e. $\sigma_{\Delta \text { PAN }}^{\%}>100 \%$ ). Furthermore, flux values determined with the MBR method which do not meet the turbulence criterion (see Sect. 2.1.2) are considered as insignificant from zero.
For the evaluation of the presented PAN fluxes, we used time periods with sufficient developed turbulence and stationarity (Foken and Wichura, 1996), represented by the quality flags 1-6 after Foken et al. (2004). Additionally, a footprint analysis and a site-specific characterisation approach (Göckede et al., 2004, 2006) were conducted, utilising a Lagrangian forward stochastic model from Rannik et al. (2000). We excluded data where the footprint area of the flux measurement included less than $80 \%$ of the target area.

\subsection{Simulation of expected PAN mixing ratio differences}

The successful application of both the HREA and the MBR method largely depends on the capability of the analytical system to resolve the mixing ratio differences $\left(\Delta \chi_{\text {PAN }}\right)$. We simulated the expected $\Delta \chi_{\text {PAN }}$ values under various meteorological conditions for the Mainz-Finthen experiment site to define the precision requirements of the analytical system and the optimal configuration for the application of the HREA (dead band) and MBR method (measurement heights). Expected $\Delta \chi_{\text {PAN }}$ values were calculated according to Eqs. (1) and (5) with $\mathrm{O}_{3}$ as a proxy scalar for the data period from 1 August to 30 September 2011.

Whereas $F_{\mathrm{O}_{3}}$ and $\Delta \chi_{\mathrm{O}_{3}}$ (MBR) could be retrieved from direct measurements, $\Delta \chi_{\mathrm{O}_{3}}$ (HREA) was retrieved by simulating the conditional sampling using the measured highfrequency time series of $\mathrm{O}_{3}$ and the vertical wind velocity. To investigate the influence of different dead bands, the simulation was performed using both fixed and hyperbolic dead bands of various sizes. For the dead band calculation and the simulation the same data pre-processing steps as during the real-time REA measurements were performed (Sect. 2.4).

The required estimate for $F_{\mathrm{PAN}}$ was derived by applying the big leaf multiple resistance approach (Hicks et al., 1987; Wesely and Hicks, 2000). The approach divides the overall resistance against deposition (inverse of the deposition velocity) of a substance into the aerodynamic resistance $\left(R_{\mathrm{a}}\right)$, the quasi-laminar boundary layer resistance $\left(R_{\mathrm{b}}\right)$ and the surface resistance $\left(R_{\mathrm{c}}\right)$ and can be used to describe unidirectional deposition fluxes, which was expected for PAN at the grassland site. $F_{\mathrm{PAN}}$ is then expressed as the ratio of the PAN concentration (PAN mixing ratio multiplied by $\rho_{\mathrm{m}}$ ) at one height and the resistances against deposition to the ground:

$F_{\mathrm{PAN}}=-\frac{1}{R_{\mathrm{a}}+R_{\mathrm{b}}+R_{\mathrm{c}}} \cdot \rho_{\mathrm{m}} \cdot \chi_{\mathrm{PAN}}$.

$R_{\mathrm{a}}$ was calculated according to Garland (1977), using the integrated stability correction function of Businger et al. (1971) modified by Högström (1988). $R_{\mathrm{b}}$ can be described according to Hicks et al. (1987) as a function of $u_{*}$, the Prandtl and Schmidt number. The latter largely depends on the molecular diffusivity of the trace gas and was found for PAN, according to data of Hicks et al. (1987), to be $\sim 1.72$. For the $R_{\mathrm{c}}$ we assumed as a rough estimate that the resistance 
(a)
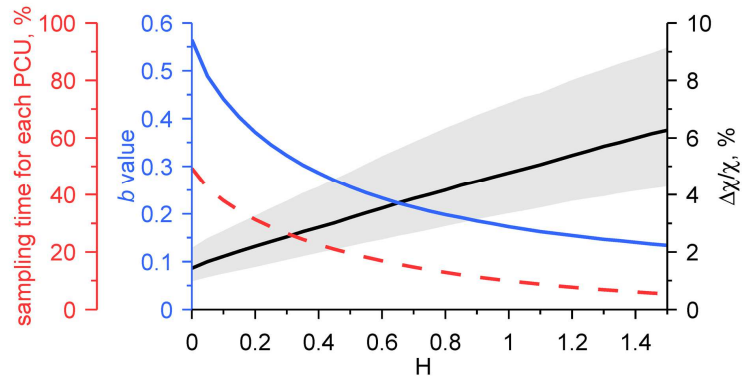

(b)

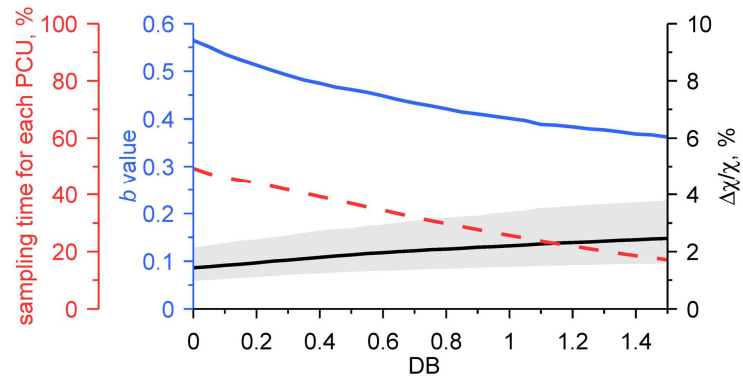

Figure 3. Effect of various dead band sizes on the expected relative PAN mixing ratio differences, the $b$ value and the sampling time for the application of the REA method. Median values are displayed and the shaded area represents the interquartile range of the expected mixing ratio differences. Variations of the $b$ value and the sampling time were only small. Shown are the results from the simulation based on data from the Mainz-Finthen grassland site for the period from 1 August to 30 September 2011 employing (a) a hyperbolic dead band with $\mathrm{O}_{3}$ as a proxy scalar and (b) a fixed dead band value scaled by $\sigma_{\mathrm{W}}$ only.

at the surface for PAN was similar to $R_{\mathrm{c}}\left(\mathrm{O}_{3}\right)$, which could be determined from the resistance approach since $F_{\mathrm{O}_{3}}$ was known.

\section{Results}

\subsection{Expected PAN mixing ratio differences}

\subsubsection{Effect of HREA dead band}

The size and type of the dead band had to be chosen carefully since it influences not only the magnitude of the sampled $\Delta \chi_{\text {PAN }}$ values but also the effective sampling time and the scalar similarity. The results from the HREA simulation analysis (Fig. 3a) show a steady increase of the relative $\Delta \chi_{\text {PAN }}$ values from a zero dead band (median: $1.4 \%$ ) to a large hyperbolic dead band of 1.5 (median: $6.3 \%$ ); at the same time the variability increases with the dead band size. As a result of the increasing $\Delta \chi_{\text {PAN }}$ values, the $b$ value decreased exponentially with increasing dead band, starting from 0.56 with no dead band to 0.14 for $H=1.5$. In the same way, the effective sampling time for each PCU decreases from $50 \%$ of the total sampling time with no dead band to $5.4 \%$ at $H=1.5$. In contrast to the relative $\Delta \chi_{\text {PAN }}$ values, both the simulation of the $b$ value and the sampling time showed only a very small variability.

Figure $3 \mathrm{~b}$ shows the results of the simulation for a fixed dead band scaled only by $\sigma_{\mathrm{w}}$. The linear increase of relative $\Delta \chi_{\text {PAN }}$ values with increasing dead band is less steep compared to a hyperbolic dead band, only resulting in median relative $\Delta \chi_{\text {PAN }}$ values of $2.5 \%$ at a dead band of $1.5 \cdot \sigma_{\mathrm{w}}$. In return, the effective sample volume per PCU is still $17 \%$ at this point.

Since the simulation yielded much higher expected $\Delta \chi_{\text {PAN }}$ with the HREA method, we chose a hyperbolic dead band of $H=1.1$ for the further simulation and the experiment. The lower sample volume associated with the hyperbolic dead band could be compensated by using a higher sample flow rate (as given in Sects. 2.4 and 2.5) through the PCUs without reaching the breakthrough of PAN.

\subsubsection{Diurnal cycle of expected PAN mixing ratio differences}

The diurnal course of the expected PAN values is shown in Fig. 4 for both the HREA and MBR method. For the HREA method, expected $\Delta \chi_{\text {PAN }}$ values were very low during nighttime (median values: $\sim-5 \mathrm{ppt}$ ), whereas absolute $\Delta \chi_{\text {PAN }}$ values increased in the morning together with both the increase of turbulent mixing and the increase of PAN mixing ratios (not shown). The average median $\Delta$ XPAN values during the day were around $-27 \mathrm{ppt}$; most values ranged between $-15 \mathrm{ppt}(0.25$ percentile) and $-50 \mathrm{ppt}(0.75$ percentile). Lowest absolute values close to zero occurred at high wind speeds under neutral stability conditions. Comparable daytime values were simulated when applying the MBR method. As found for the HREA method, lowest values were reached under neutral conditions. During nighttime, expected $\Delta \chi_{\text {PAN }}$ values were generally larger but also showed a high variability with median values between 23 and $117 \mathrm{ppt} . \Delta \chi_{\text {PAN }}$ values of up to $300 \mathrm{ppt}$ were calculated under conditions with limited turbulent exchange. However, under these conditions fluxes are expected to be very small and might be below the turbulence criterion (Sect. 2.1.2).

\subsection{Calibration}

The aim of the regularly performed calibrations was (a) to determine the point of saturation of the PCUs, which was important for setting the sample flow; (b) to investigate the relationship between peak integral, sample volume and PAN mixing ratio; and (c) to determine the precision and limit of detection (LOD) for a single mixing ratio measurement.

Experiments testing different flow rates through the PCUs showed that the time after which the PCU was saturated decreased linearly with an increasing sample flow rate. For a sample flow rate of $1 \mathrm{~mL} \mathrm{~min}^{-1}$ (STP), as set during the 


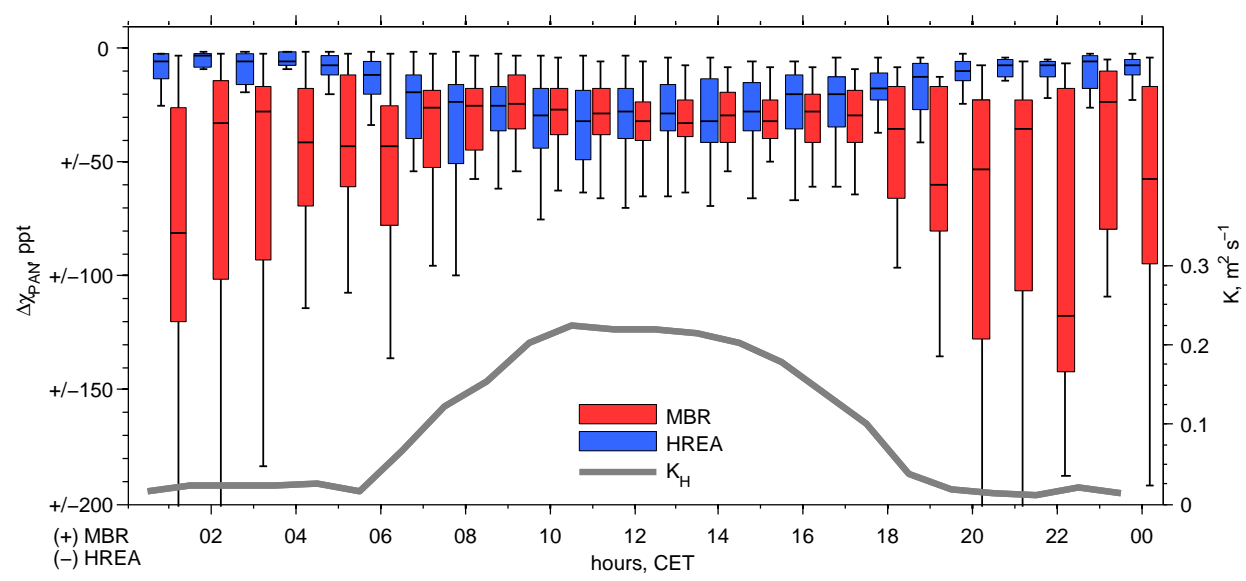

Figure 4. The expected absolute PAN mixing ratio differences using both the HREA and MBR method presented as diurnal cycles using hourly boxplot statistics. Shown are the results from the simulation based on data from the Mainz-Finthen grassland site for the period from 1 August to 30 September 2011. In addition, the median turbulent exchange coefficient $K_{\mathrm{H}}$ is displayed, which was calculated with the aerodynamic approach using the universal stability functions for the sensible heat flux of Businger et al. (1971) modified by Högström (1988). For most of the night-time differences for the MBR method the turbulence criterion (i.e. $u_{*}<0.07 \mathrm{~m} \mathrm{~s}^{-1}$ according to Liu and Foken, 2001) is not fulfilled and the flux calculation is not possible.

HREA application, the saturation occurred after $\sim 12 \mathrm{~min}$. For the average sampling time per PCU of $3.83( \pm 0.77)$ min (with $H=1.1$ ) this was sufficient to guarantee that the frontal zone of PAN would not have eluted from the PCUs during sampling. Since the volume (and not mass) flow rate of the sample gas controls the speed of the frontal zone in the PCU, the saturation point is dependent on the pressure in the PCUs. During the HREA operation the pressure measured downstream of the PCUs ranged between 718.2 and $739.8 \mathrm{hPa}$. These variations were mainly caused by the diurnal course in ambient air temperature. The standard deviation of the short-term signal over one sampling period was $\pm 0.7 \mathrm{hPa}$. The mean pressure during the MBR operation was higher, ranging between 901.3 and $927.6 \mathrm{hPa}( \pm 0.5 \mathrm{hPa})$, which was due to the employment of two instead of one sample line. This led to a longer time until saturation of the PCU was reached, which allowed us to set the sampling time during MBR operation to $15 \mathrm{~min}$.

We generally found, on the one hand, a linear relationship between the peak integral and the sample volume for different PAN mixing ratios (Fig. 5a), and, on the other hand, between the peak integral and the PAN mixing ratio at different sampling times (Fig. 5b).

\subsection{Side-by-side measurements}

Although all side-by-side measurements were performed during good weather conditions and covered a period of one diurnal cycle or more, the range of prevailing PAN mixing ratios was large (Fig. 6). During both periods, SBS_HREA 1 and SBS_MBR 2 PAN mixing ratios below 200 and $400 \mathrm{ppt}$ were measured, respectively. Due to the low mixing ratios during SBS_HREA 1 we included the results from the calibration with PAN mixing ratios of $1080 \mathrm{ppt}( \pm 50 \mathrm{ppt})$ During SBS_HREA 2 and SBS_MBR 1 higher PAN mixing ratios above $200 \mathrm{ppt}$ prevailed, reaching up to 700 and $1400 \mathrm{ppt}$, respectively. For all side-by-side measurements the linear regressions show systematic differences between both PCUs, which were corrected for by using PCU 1 as a reference and adjusting the signals from PCU 2 with the orthogonal fit function. For the periods between the side-byside measurements, we linearly interpolated the values for the slope and intercept given in Table 1.

As shown in Table 1, the derived precisions (Sect. 2.6.2) varied between the different experiments. While for the MBR operation the precision was determined as $15.2 \mathrm{ppt}$ before and as $4.1 \mathrm{ppt}$ during the flux measurement experiment, the precision before and after the HREA flux measurements was much lower, namely 32.5 and $59.9 \mathrm{ppt}$, respectively (Table 1). The significantly larger scatter during the HREA sideby-side measurements was partly corrected for (for details see Sect. SM4 in the Supplement and Sect. 4.2) and the precision was improved by $50 \%$, to 17.9 and $26.1 \mathrm{ppt}$, respectively (see Table 1 and Fig. 6a). This correction was applied to all data in the post-processing of the HREA measurements.

As defined in Sect. 2.6.3, the precision values presented in Table 1 are considered as the detection limit for $\Delta \chi_{\text {PAN }}$. This means that $\Delta \chi_{\text {PAN }}$ values below are associated with $\sigma_{\Delta \text { PAN }}^{\%}>$ $100 \%$.

\subsection{PAN flux measurements}

\subsubsection{HREA measurements}

During the period of the HREA measurements (20 to 27 September 2011) dry and mostly sunny autumn weather 
Table 1. Results from the side-by-side measurements during MBR and HREA operation, showing the parameters of the orthogonal fit functions. The residuals of the regression were used to determine the random error of the PAN mixing ratio differences $\left(\sigma_{\Delta \mathrm{PAN}}\right)$.

\begin{tabular}{lllrrrrrr}
\hline & Period & Date & Duration [hrs] & $n$ & Slope & Intercept [mV s mL $\left.{ }^{-1}\right]$ & $R^{2}$ & $\sigma_{\Delta \text { PAN }}[\mathrm{ppt}]$ \\
\hline MBR & SBS_MBR 1 & 18-19 Aug 2011 & 17.75 & 36 & 1.08 & 3294.3 & 0.9958 & 15.2 \\
& SBS_MBR 2 & 29-30 Aug 2011 & 33.25 & 67 & 1.05 & -298.5 & 0.9972 & 4.1 \\
\hline HREA & SBS_HREA 1 & 19-20 Sep 2011 & 32.0 & $43^{*}$ & 0.86 & 142.0 & 0.9931 & 32.5 \\
& (corrected) & 19-20 Sep 2011 & 32.0 & $43^{*}$ & 0.88 & 73.3 & 0.9995 & 17.9 \\
& SBS_HREA 2 & 27-28 Sep 2011 & 29.0 & 39 & 0.70 & 1819.3 & 0.7707 & 59.5 \\
& (corrected) & 27-28 Sep 2011 & 29.0 & 39 & 0.83 & 1228.8 & 0.9233 & 26.1 \\
\hline
\end{tabular}

* Including calibration data.

(a)

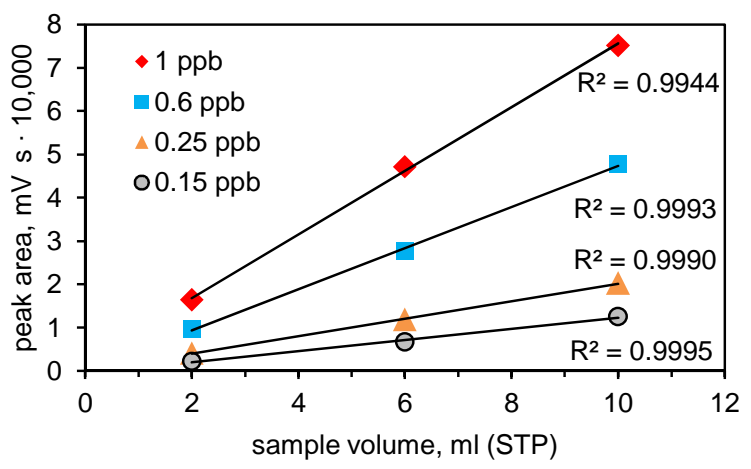

(b)

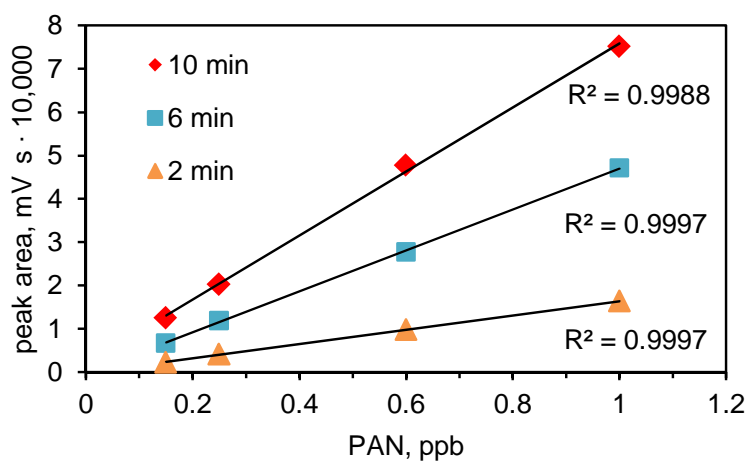

Figure 5. Results of a multi-step calibration experiment illustrating the linear relationship between (a) the area of the PAN peak and the sample volume (STP) for various PAN mixing ratios as well as (b) the area of the PAN peak and PAN mixing ratios for different loading times of the PCUs. Since the flow rate through the preconcentration unit was regulated by a mass flow controller, both the loading time and the sample volume are linearly proportional to the mass of the sampled air volume.

conditions prevailed, with maximum daytime temperatures of 20 to $25^{\circ} \mathrm{C}$ and minimum temperatures of 8 to $17^{\circ} \mathrm{C}$ during the night. While on most days atmospheric conditions were unstable during daytime and stable during nighttime, on 22 September mostly neutral conditions prevailed during daytime and on 24 September only slightly unstable conditions were encountered. On these days, the daytime average maximal wind speeds and the average $u_{*}$ values (see Fig. 7a) reached 4.5 and $0.5 \mathrm{~m} \mathrm{~s}^{-1}$, respectively, which were much larger in comparison to the other days. The higher turbulent exchange during those days is represented by higher values of $\sigma_{\mathrm{w}}$ (Fig. 7a), which has an impact on the REA flux (Eq. 1). During the other days, the mean maximum value of $\sigma_{\mathrm{w}}$ during daytime was $0.10 \pm 0.07 \mathrm{~m} \mathrm{~s}^{-1}$, which is lower than the respective annual mean for the site $\left(\sigma_{\mathrm{w}}=0.18 \pm 0.15 \mathrm{~m} \mathrm{~s}^{-1}\right)$ and during the period of the MBR measurements $\left(\sigma_{\mathrm{w}}=0.13 \pm 0.11 \mathrm{~m} \mathrm{~s}^{-1}\right)$.

Since $\mathrm{O}_{3}$ was used as a proxy scalar for the determination of the HREA dead band and the $b$ value, the similarity between PAN and $\mathrm{O}_{3}$ mixing ratios is shown in Fig. 7b. On most days both quantities feature a simultaneous increase of their mixing ratios in the morning and a diurnal maximum in the afternoon between 16:00 and 17:00 CET with maximal PAN mixing ratios ranging between 243 and $1172 \mathrm{ppt}$ and $\mathrm{O}_{3}$ mixing ratios between 41 and $57 \mathrm{ppb}$. On 22 September the daytime PAN mixing ratios did not show a significant increase, which was probably caused by both reduced photochemical production due to overcast periods and low- $\mathrm{NO}_{\mathrm{x}}$ conditions, as well as downward transport of PAN-poor air masses due to the enhanced turbulent mixing.

The values for $\Delta \chi_{\mathrm{O}_{3}}$, calculated from the high-frequency $\mathrm{O}_{3}$ data with a dead band size of $H=1.1$, were mostly negative and reached minimal values of $-3 \mathrm{ppb}$ in the late afternoon, indicating a deposition flux (Fig. 7c). Not considering the $\Delta \chi_{\mathrm{O}_{3}}$ values which are below the detection limit $\left(\sigma_{\Delta \mathrm{O}_{3}}^{\%}>100 \%\right)$, few positive values were observed during night-time, which might be caused by limited turbulent exchange and small $\mathrm{O}_{3}$ fluxes at night (Fig. 7d). The $\mathrm{O}_{3}$ eddy covariance fluxes showed a clear diurnal course with maximal deposition fluxes between -5 and $-10 \mathrm{nmol} \mathrm{m}^{-2} \mathrm{~s}^{-1}$ during daytime.

The $b$ values, which were determined from the $\mathrm{O}_{3}$ flux and $\Delta \chi_{\mathrm{O}_{3}}$ values, are shown in Fig. 7e. The median was 0.21 , which is slightly higher than the median value $(0.16)$ from the simulation analysis with a dead band size of $H=1.1$ (Fig. 3a). However, as found by other studies (e.g. Oncley et al., 1993; Beverland et al., 1996), calculated $b$ values may 
(a)

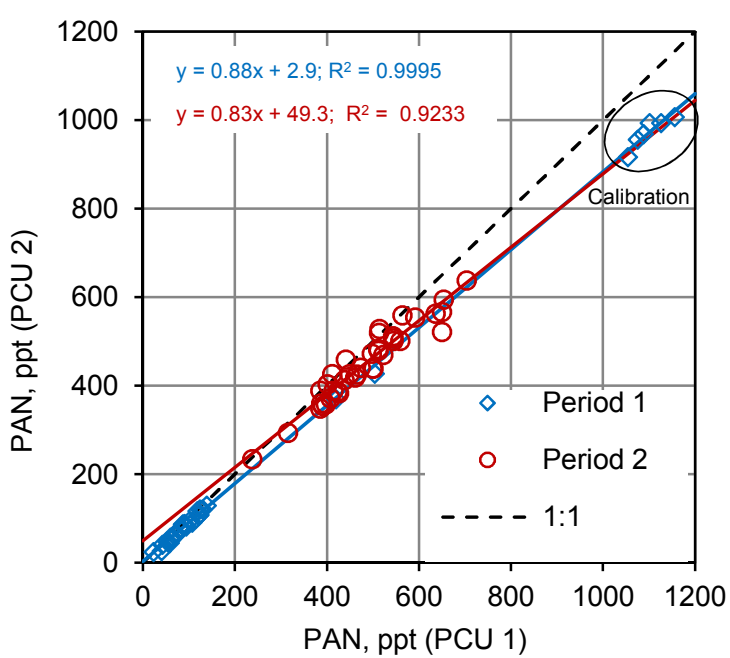

(b)

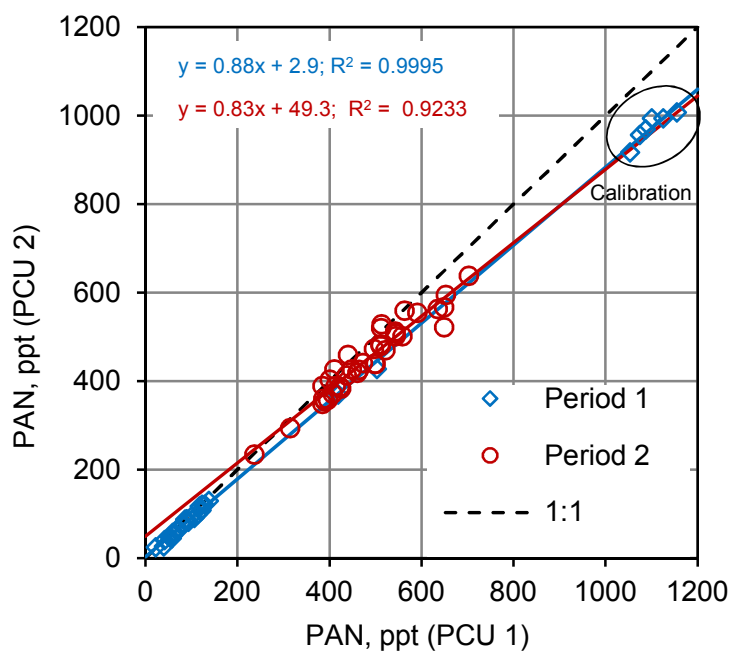

Figure 6. Results from side-by-side measurements for two periods during (a) HREA operation after correction for pressure effects (see Sect. SM4 in the Supplement) and (b) MBR operation of the PAN flux measurement system. For the conversion to PAN mixing ratios, the calibration coefficient from PCU 1 was applied for both PCU 1 and PCU 2 to illustrate the systematic deviation from the $1: 1$ slope.

vary significantly (interquartile range of 0.19 to 0.30 in this study). The variation was particularly large for conditions with weak turbulence $\left(u_{*}<0.1 \mathrm{~m} \mathrm{~s}^{-1}\right)$ and small sensible heat fluxes of $\pm 5 \mathrm{~W} \mathrm{~m}^{-2}$. Under these conditions, which occurred mostly during night-time, both the conditional mixing ratio differences $\Delta \chi_{\mathrm{O}_{3}}$ and the $\mathrm{O}_{3}$ eddy covariance flux $\left(>-0.5 \mathrm{nmol} \mathrm{m}^{-2} \mathrm{~s}^{-1}\right)$ changed sign occasionally (Fig. $7 \mathrm{c}$ and d) and were also characterised by higher random errors.

Figure $7 f$ shows the measured PAN mixing ratio differences, $\Delta \chi_{\text {PAN }}$, between the two PCUs for updraft and downdraft events. Most $\Delta \chi_{\text {PAN }}$ values did not exceed the detection limit $\left(\sigma_{\Delta \mathrm{PAN}}^{\%}>100 \%\right)$ determined from the side-by-side measurements (Table 1). The values above the detection limit are randomly distributed throughout the time series and still seem to be within the noise of the mixing ratio measurement. Only on 25 September were some significant $\Delta \chi_{\text {PAN }}$ values detected, which reached up to $-150 \mathrm{ppt}$, indicating a net deposition flux.

As a consequence of the low $\Delta \chi_{\text {PAN }}$ values, PAN fluxes during the HREA measurement period were in most cases below the flux detection limit (Fig. $7 \mathrm{~g}$ ) as defined in Sect. 2.6.3. Only on 25 September was a deposition flux of up to $-0.4 \mathrm{nmol} \mathrm{m} \mathrm{m}^{-2} \mathrm{~s}^{-1}$ found. For the remaining values above the flux detection limit $(n=21)$ a median random flux error of $\pm 0.078 \mathrm{nmol} \mathrm{m}^{-2} \mathrm{~s}^{-1}$ for daytime and $\pm 0.020 \mathrm{nmol} \mathrm{m}^{-2} \mathrm{~s}^{-1}$ for night-time (Fig. 9a) was determined. The daytime flux errors were mainly attributed to the error of $\Delta \chi_{\text {PAN }}$ with a median error contribution of $50 \%$ (Fig. 9b). The magnitude of the covariance term in the error propagation equation (Sect. SM3 in the Supplement) was largely governed by the error of $\Delta \chi_{\mathrm{O}_{3}}$. During night-time all terms had a similar impact on the total flux uncertainty.

\subsubsection{MBR measurements}

In general, the weather conditions during the MBR measurements (19 August to 4 September 2011) featured not only higher temperatures and stronger wind speeds, but also more frequent isolated rain events than during the period of the HREA measurements. The MBR measurements can be divided into two sections (SI+SII) according to the prevailing weather conditions: (SI) 20 to 26 August was a sunny period with occasional cloud cover and one short rain event on 21 August. Stable stratification at night and unstable stratification during daytime, sometimes leading to free convection, prevailed. Daily maximal temperatures reached up to $34{ }^{\circ} \mathrm{C}$, while maximal wind speeds in the afternoon were on average $3.5 \mathrm{~m} \mathrm{~s}^{-1}$. Period SI was terminated by a passing cold front in the late afternoon of 26 August accompanied by rainfall together with a temperature drop and increasing wind speeds. (SII) The period from 30 August to 4 September was a dry period with mostly sunny days under the influence of high-pressure systems with increasing temperatures and lower wind speeds (mean diurnal maximum: $2.3 \mathrm{~m} \mathrm{~s}^{-1}$ ), resulting also in lower $u_{*}$ values (Fig. 8a) as during SI. During that period also stable stratification at night and unstable stratification during daytime, partially leading to free convection, prevailed. The period from 27 to 30 August is not considered here due to the performance of the side-by-side measurements (Sect. 3.3), extended calibrations and maintenance of the GC-ECD in this period.

The effect of the varying weather conditions on $\mathrm{O}_{3}$ and PAN mixing ratios is shown in Fig. 8b. On most days during period SI and SII a clear diurnal course of $\mathrm{O}_{3}$ mixing ratios is visible with maximum values of $65 \mathrm{ppb}$, while during SII the development of strong nocturnal inversion layers lead to nearly complete $\mathrm{O}_{3}$ depletion at night. The diurnal course of PAN mixing ratios was strongly coupled to that of $\mathrm{O}_{3}$, 
(a)
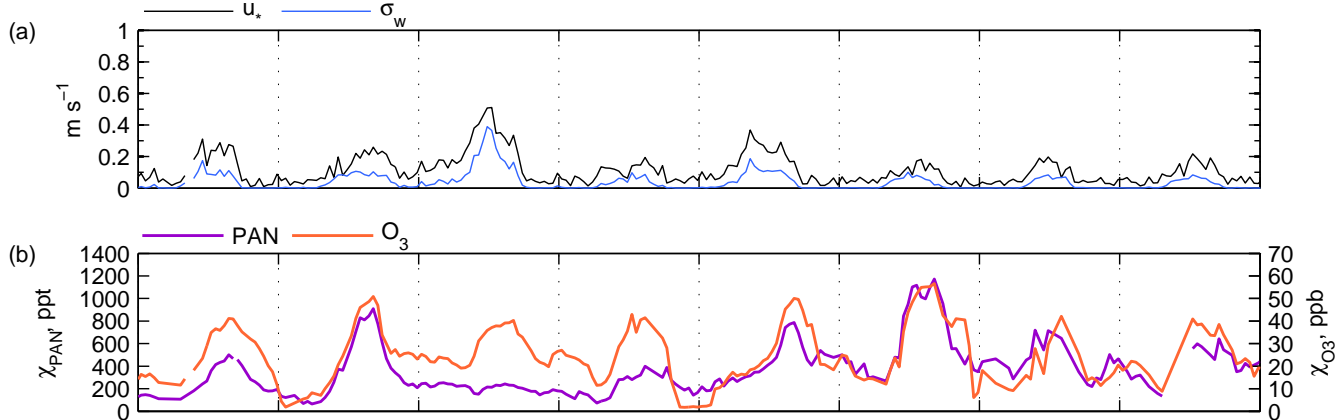

(c)

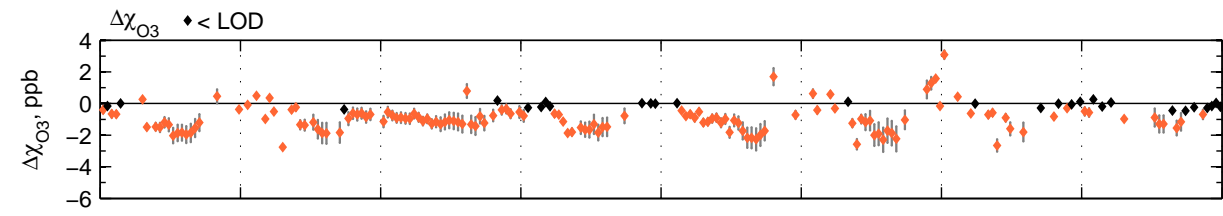

(d) $T^{\top}$

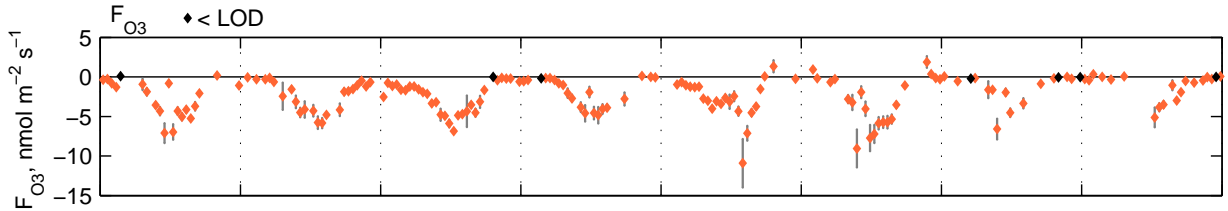

(e)
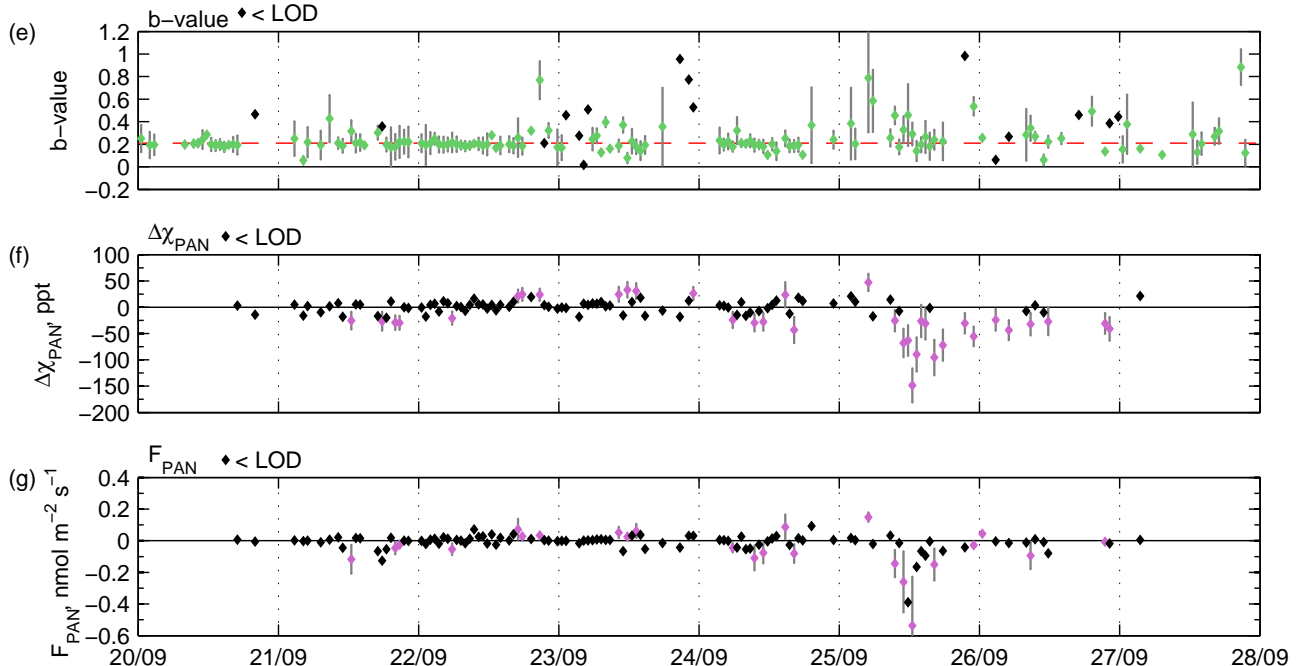

Figure 7. Results from the HREA experiment at the Mainz-Finthen grassland site from 20 to 27 September 2011 showing (a) $u_{*}$ and $\sigma_{\mathrm{w}}$, (b) PAN and $\mathrm{O}_{3}$ mixing ratios, (c) $\Delta \chi_{\mathrm{O}_{3}}$, (d) $F_{O_{3}}$, (e) $b$ value, (f) $\Delta \chi$ PAN and (g) $F_{\text {PAN }}$. Grey error bars denote random error. Black data points indicate values below the detection limit (for details see text).

although on some days (e.g. 26 August and early morning of 4 September) the decline of PAN mixing ratios starting in the late afternoon was much stronger. During nights with strong $\mathrm{O}_{3}$ depletion, PAN mixing ratios of more than $200 \mathrm{ppt}$ prevailed. Daily maxima of PAN mixing ratios ranged from $400 \mathrm{ppt}$ to more than $1200 \mathrm{ppt}$.

The $\Delta \chi_{\mathrm{O}_{3}}$ values and the $\mathrm{O}_{3}$ flux, which were used to calculate the transfer velocity, are displayed in Fig. $8 \mathrm{c}$ and d. While during daytime $\Delta \chi_{\mathrm{O}_{3}}$ values were on average $2.0 \mathrm{ppb}( \pm 0.6 \mathrm{ppb})$, the differences during night-time were much larger and reached up to $18 \mathrm{ppb}$ during strong stable stratification. During daytime some values were below the detection limit $\left(\sigma_{\Delta \mathrm{O}_{3}}^{\%}>100 \%\right) . \mathrm{O}_{3}$ deposition fluxes were higher than during HREA measurements and reached up to $-12 \mathrm{nmol} \mathrm{m}^{-2} \mathrm{~s}^{-1}$ during daytime, with an average maximum of $-8 \mathrm{nmol} \mathrm{m}^{-2} \mathrm{~s}^{-1}$. During night-time $\mathrm{O}_{3}$ fluxes were small except on nights with neutral stratification, when fluxes of up to $-5 \mathrm{nmol} \mathrm{m}^{-2} \mathrm{~s}^{-1}$ prevailed.

The resulting transfer velocity (Fig. 8e) representing the layer between 0.8 and $4.0 \mathrm{~m}$ a.g.l. showed average daytime values of $0.08 \mathrm{~m} \mathrm{~s}^{-1}\left( \pm 0.06 \mathrm{~m} \mathrm{~s}^{-1}\right)$, whereas during night- 
(a)
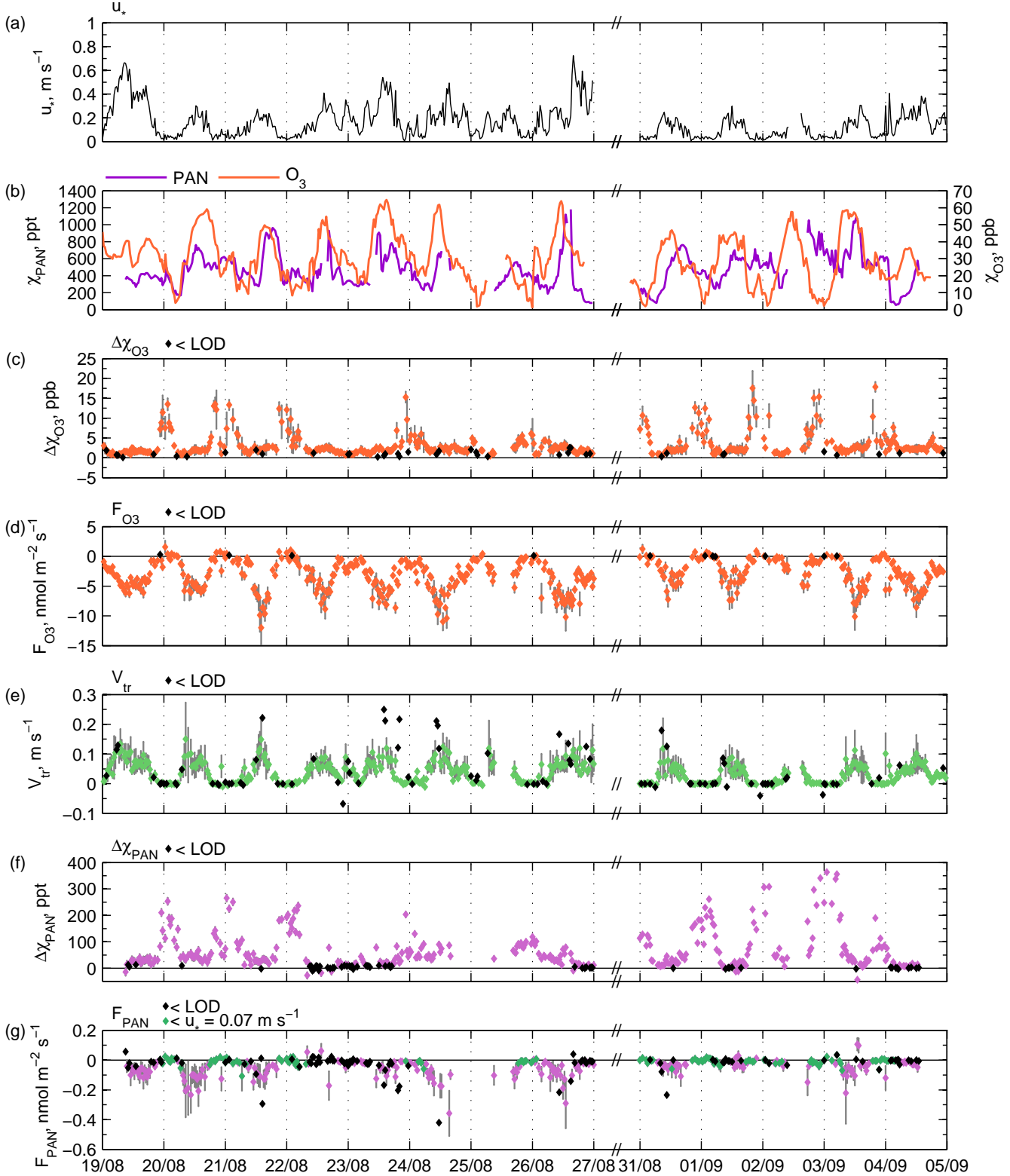

Figure 8. Results from the MBR experiment at the Mainz-Finthen grassland site from 19 August to 4 September 2011 showing (a) $u_{*}$, (b) PAN and $\mathrm{O}_{3}$ mixing ratios, (c) $\Delta \chi_{\mathrm{O}_{3}}$, (d) $F_{\mathrm{O}_{3}}$, (e) $v_{\text {tr }}$, (f) $\Delta \chi_{\mathrm{PAN}}$ and (g) $F_{\mathrm{PAN}}$. Grey error bars denote random error. Black data points indicate values below the detection limit (for details see text). Red data points denote periods where $u_{*}<0.07 \mathrm{~m} \mathrm{~s}^{-1}$.

time the transfer velocity was close to zero and often below the detection limit $\left(\sigma_{v_{\text {tr }}}^{\%}>100 \%\right)$.

As a result of the limited turbulent exchange at night, $\Delta \chi_{\text {PAN }}$ values reached up to $400 \mathrm{ppt}$ (Fig. 8f). In general, the course of night-time $\Delta \chi_{\text {PAN }}$ compared well to $\Delta \chi_{\mathrm{O}_{3}}$, indicating scalar similarity of PAN and $\mathrm{O}_{3}$. On average, the daytime $\Delta \chi_{\mathrm{PAN}}$ values were $27 \mathrm{ppt}( \pm 30 \mathrm{ppt})$. While on some days they were clearly different from zero, on other days they were close to zero and did not exceed the detection limit $\left(\sigma_{\Delta \mathrm{PAN}}^{\%}>100 \%\right)$ determined from the side-by-side measurements (Table 1).
On those days with significant daytime $\Delta \chi_{\text {PAN }}$ values also a significant daytime PAN deposition flux was visible and reached up to $-0.2 \mathrm{nmol} \mathrm{m}^{-2} \mathrm{~s}^{-1}$ (Fig. 8g). On other days, when daytime $\Delta \chi_{\text {PAN }}$ values were smaller or not different from zero, PAN fluxes were below the flux detection limit (for definition see Sect. 2.6.3). Considering only values above the flux detection limit, daytime PAN deposition was on average $-0.07 \mathrm{nmol} \mathrm{m}^{-2} \mathrm{~s}^{-1}$ during that period. The corresponding median random flux error was $\pm 0.033 \mathrm{nmol} \mathrm{m}^{-2} \mathrm{~s}^{-1}$ (Fig. 9c) and mainly consisted of the errors of $\Delta \chi_{\mathrm{PAN}}$ and $\Delta \chi_{\mathrm{O}_{3}}$ with median error contributions 

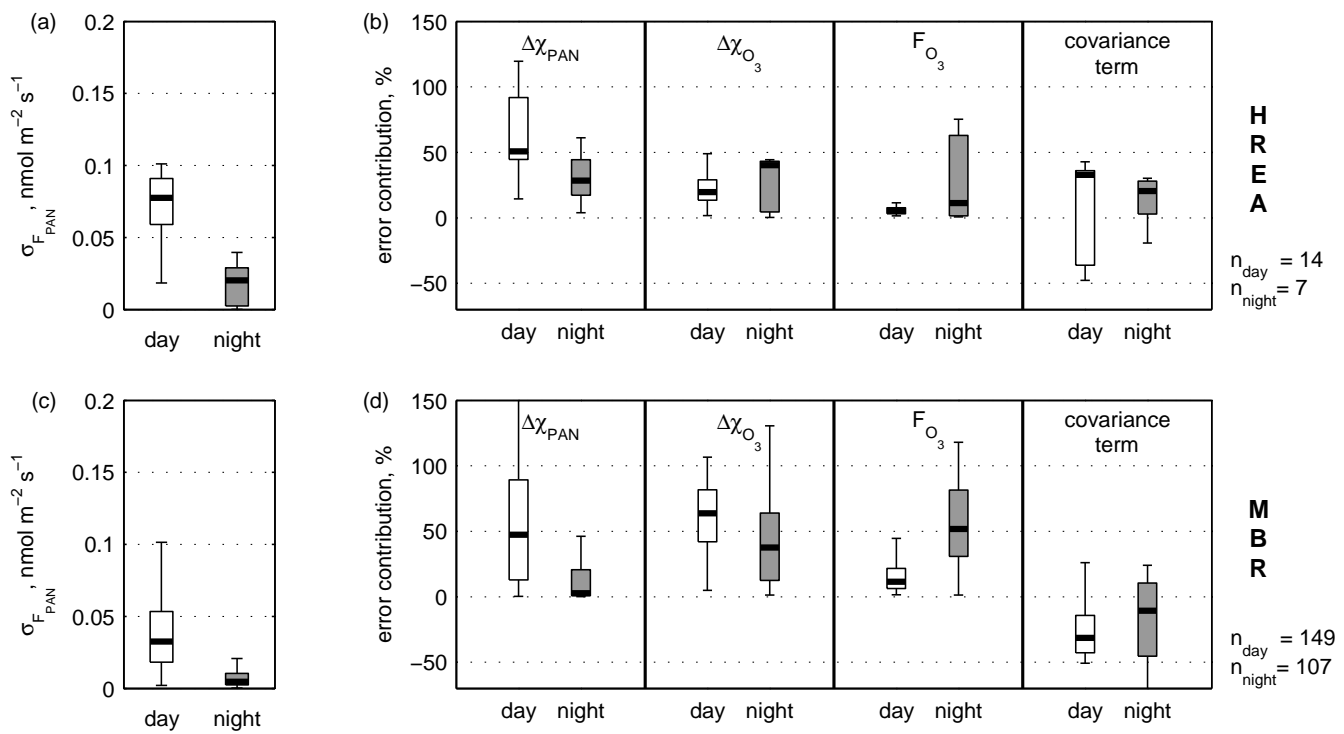

Figure 9. Boxplot statistics of random errors for the HREA (upper panel) and MBR (lower panel) measurements during day and nighttime at the Mainz-Finthen grassland site. (a) and (c): absolute random errors of the PAN flux; (b) and (d): relative contribution to the total random flux error of the individual components used in the error propagation method (Sect. SM3 in the Supplement). The covariance term accounts for a possible correlation of the individual error terms and can be positive or negative. Values below the flux detection limit were not considered, which did not have a significant impact on the displayed boxplot statistics.

of 52 and $65 \%$, respectively (Fig. 9d). At night-time PAN fluxes were negligible or fell below the turbulence criteria when $u_{*}<0.07 \mathrm{~m} \mathrm{~s}^{-1}$ (see Sect. 4.1 .3 for discussion). The magnitude of the night-time random flux error (median: $\pm 0.005 \mathrm{nmol} \mathrm{m}^{-2} \mathrm{~s}^{-1}$ ) was mainly attributed to the errors of $\Delta \chi_{\mathrm{O}_{3}}$ and the $\mathrm{O}_{3}$ flux (median contribution: 38 and $52 \%$, respectively), while the error of $\Delta \chi$ PAN was insignificant (median contribution: $5 \%$ ).

\section{Discussion}

\subsection{Performance of the PAN flux measurement system}

\subsubsection{Performance of the GC-ECD}

The uncertainties in the PAN fluxes were mainly caused by the error of $\Delta \chi_{\text {PAN }}$. Hence, a precision and performance of the GC-ECD analysis is a main criterion for the performance of the flux measurement system. The LOD of absolute PAN mixing ratios was derived from the height of the residual peak compared to the baseline noise during calibration with zero air and determined as $5 \mathrm{ppt}$ ( $3 \sigma$ definition). This value compares well to other GC-ECD systems which employed a capillary column for the pre-concentration of PAN (Jacobi et al., 1999; Mills et al., 2007). For systems without pre-concentration LODs above $10 \mathrm{ppt}$ (Schrimpf et al., 1995; Fischer et al., 2011) ranging up to $30 \mathrm{ppt}$ or higher (Volz-Thomas et al., 2002; Zhang et al., 2009) were reported previously. Flocke et al. (2005) and Williams et al. (2000) designed their systems for aircraft measurements and achieved a much lower LOD ( $3 \sigma$ definition) without preconcentration, $3 \mathrm{ppt}$ and $<5 \mathrm{ppt}$, respectively. During calibration experiments with $850 \mathrm{ppt}$ PAN we found a precision $(1 \sigma)$ of $1.5 \%$ in the gradient mode and of $3 \%$ in the HREA mode (for discussion see also Sect. 4.2). These values are within the range of other recent GC-ECD systems, which reported a $1 \sigma$ precision for PAN of $1 \%$ (Zhang et al., 2012) or $3 \%$ (at $470 \mathrm{ppt}$ ) (Fischer et al., 2011).

Although the performance of the GC-ECD was similar or even better than that of other state-of-the-art GC-ECD systems, the derived precision value at a single mixing ratio does not necessarily apply for the whole range of prevailing PAN mixing ratios. In addition, for the application of the HREA and MBR method the precision of $\Delta \chi_{\text {PAN }}$ is important. As presented in Sect. 3.3, the precision for the $\Delta \chi_{\text {PAN }}$ values derived from the side-by-side measurements ranged between 17.9 and $26.1 \mathrm{ppt}$ for the HREA measurements and between 4.1 and 15.2 ppt for the MBR (Table 1). The precision was largely independent from the prevailing PAN mixing ratios, which is the reason why we applied a constant absolute random error for the whole range of PAN mixing ratios. For the HREA operation the experimentally determined precisions were as high as the simulated daytime differences (Sect. 2.7), which explains the large errors of the PAN flux.

\subsubsection{Effect of HREA timing}

For the HREA measurements, an accurate conditional sampling of updraft and downdraft air masses into the according PCUs is important, especially at high eddy reversal 
frequencies (e.g. Baker et al., 1992; Moravek et al., 2013). Besides a correct online coordinate rotation of the wind vector and the appropriate choice of the dead band size and proxy scalar, this required a precise timing of the switching of the splitter valves and the investigation on highfrequency attenuation effects of the inlet tube. As presented in Sect. SM2 in the Supplement, the electronic time lag between exceeding the dead band threshold and switching of the splitter valves was less than $20 \mathrm{~ms}$ and could be neglected (Moravek et al., 2013). As shown by Moravek et al. (2013), the application of the online cross-correlation method corrected for the sensor separation effect, but was associated with a random error of $\pm 100 \mathrm{~ms}$. The resulting flux error was determined using the relationship between flux loss and the eddy reversal frequency (Moravek et al., 2013). During the experiment, the eddy reversal frequency ranged from 3.0 to $12.4 \mathrm{~Hz}$ (median: $7.6 \mathrm{~Hz}$ ) for the applied hyperbolic dead band of $H=1.1$. A simulation analysis (Moravek et al., 2013) yielded a random flux error due to the error of the online cross-correlation method between \pm 0.6 and $\pm 9.9 \%$ (median: $4.0 \%$ ). For the effect of high-frequency attenuation a cut-off frequency of $1.2 \mathrm{~Hz}$ was determined for the $21.5 \mathrm{~m}$ long inlet tube (Moravek et al., 2013), which led to an underestimation of the PAN flux ranging from 1.8 to $31.4 \%$ (median: $11.8 \%$ ), which was corrected for in the post-processing.

\subsubsection{Random flux error under varying meteorological conditions}

A main criterion for the performance of the PAN flux measurement system is the random flux error. As presented in Sect. 3.4 and in Fig. 9, the flux errors were large compared to the observed fluxes and were caused to a large extend by the error of $\Delta \chi_{\text {PAN }}$, but also by the error of $\Delta \chi_{\mathrm{O}_{3}}$. This was the case for daytime MBR fluxes, when the standard deviation of $\Delta \chi_{\mathrm{O}_{3}}$ is large at high $\mathrm{O}_{3}$ mixing ratios.

The difference between the daytime and night-time flux error indicates that the flux error does not only depend on the performance of the method but also on the meteorological conditions. Considering the error of $\Delta \chi_{\text {PAN }}$ as the largest fraction of the flux error, we estimate values of $\Delta \chi_{\text {PAN }}$ that would have to be measured with either HREA or MBR to obtain fluxes with a certain minimum precision under varying meteorological conditions.

For the MBR method, the required $\Delta \chi_{\text {PAN }}$ values are obtained for a certain relative random flux errors $\left(\sigma_{F_{\mathrm{PAN}}}^{\%}\right.$ in $\left.\%\right)$ by

$\Delta \chi_{\mathrm{PAN}}\left(\sigma_{F_{\mathrm{PAN}}}^{\%}\right)=\frac{\sigma_{F_{\mathrm{PAN}}}}{v_{\mathrm{tr}}\left(u_{*}\right) \cdot \sigma_{F_{\mathrm{PAN}}}^{\%}}$,

where $\sigma_{F_{\mathrm{PAN}}}$ is the absolute flux error derived from the error propagation method. Here, $v_{\text {tr }}$ is determined as a function of $u_{*}$ via the aerodynamic approach, using the integrated stability correction functions $(\Psi)$ of Businger et al. (1971)

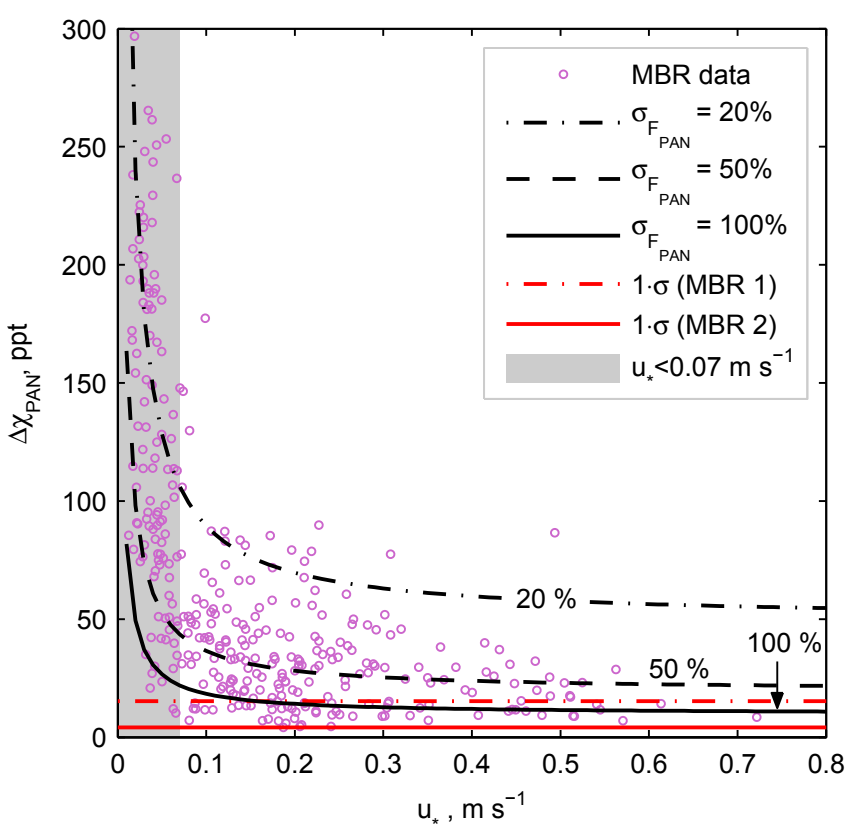

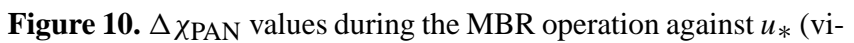
olet circles) are shown together with fitted lines of relative random flux errors of 20,50 and $100 \%$ (black lines) at the Mainz-Finthen grassland site. The red lines mark the precision for the $\Delta \chi_{\text {PAN }}$ measurement determined from side-by-side measurements. Values below this precision were excluded from the plot. The grey area with $u_{*}<0.07 \mathrm{~m} \mathrm{~s}^{-1}$ indicates fluxes with high relative random errors due to limited turbulent exchange

modified by Högström (1988):

$v_{\mathrm{tr}}=-\frac{k \cdot u_{*}}{\ln \frac{z_{2}}{z_{1}}-\Psi\left(\frac{z_{2}}{L}\right)+\Psi\left(\frac{z_{1}}{L}\right)}$,

where $\kappa$ is the von Kármán constant and $z_{1}$ the lower and $z_{2}$ the upper height of the gradient system. Finally, $\Delta \chi_{\mathrm{PAN}}\left(\sigma_{F_{\mathrm{PAN}}}^{\%}\right)$ is expressed as a function of $u_{*}$, representing the turbulent and micrometeorological conditions, for different relative random flux errors. Figure 10 shows the hyperbolic fit functions for $\sigma_{F_{\mathrm{PAN}}}^{\%}$ of 20,50 and $100 \%$ together with the measured $\Delta \chi_{\mathrm{PAN}}$ values during the MBR operation. While for higher $u_{*}$ the $\sigma_{F_{\mathrm{PAN}}}^{\%}$ values are quite constant for a certain $\Delta \chi_{\text {PAN }}$ value, below $u_{*}=0.07 \mathrm{~m} \mathrm{~s}^{-1}$ the flux error increases rapidly. The latter value is also given by Foken (2008) as a limit for MBR measurements and, hence, was used in the definition of the flux detection limit (Sect. 2.6.3). According to the error lines in Fig. 10 and not considering values below the flux detection limit, we find that $47 \%$ of the measured PAN fluxes are associated with a relative random error of between 20 and $50 \%$, and $27 \%$ between 50 and $100 \%$. Only a few values $(8 \%)$ showed a relative flux error below $20 \%$ and some $(18 \%)$ above $100 \%$. 
Using the same approach for the HREA measurements to determine the influence of the meteorological conditions on $\sigma_{F_{\text {PAN }}}^{\%}$ was not successful. A clear relationship between the required $\Delta \chi_{\text {PAN }}$ values and $u_{*}$ was not found due to the higher scatter of the determined $\sigma_{F_{\mathrm{PAN}}}$ values. For the daytime fluxes, the errors during HREA operation were on average twice as high as during MBR operation (see Fig. 9a and c), which can mainly be attributed to the lower precision of the analysing unit (see Sect. 3.3). However, it has to be noted that the HREA measurements took place in September and deposition fluxes to vegetation are lower than during the MBR measurements in August. On the one hand, the surface resistance was higher due to a higher fraction of dead grass species and a reduced stomata opening of the green plant material. For that reason it is also unlikely that prolonging the measurement period would have improved the precision of the mean HREA fluxes significantly. On the other hand, during the HREA measurement period $\sigma_{\mathrm{W}}$ values, which reflect the magnitude of turbulent exchange (Eq. 1), were below the annual average and also lower than during MBR period. Hence, in general lower fluxes due to the prevailing conditions are an additional obvious reason for the lower quality of the HREA measurements.

As was outlined in Sect. 1, the flux errors derived by other studies, which measured direct PAN exchange fluxes in the past, are also significant and vary depending on the chosen method. Doskey et al. (2004) give a rough estimate of the expected flux errors ranging between 45 and $450 \%$ for daytime fluxes. They assume at a deposition velocity of $1 \mathrm{~cm} \mathrm{~s}^{-1}$ a vertical mixing ratio difference of $1-10 \%$ of the mean mixing ratio and an error of $\Delta \chi_{\mathrm{PAN}}$ of $4.5 \%$ determined from the PAN calibration. However, we find that the most reliable method to determine the error of $\Delta \chi_{\text {PAN }}$ are side-by-side measurements at the field site to retrieve the error characteristics over the whole potential range of ambient air PAN mixing ratios. The flux error using the eddy covariance technique with a CIMS (Turnipseed et al., 2006; Wolfe et al., 2009) was found to be less (25-60\%), although the uncertainty for a single concentration measurement is larger than with the GC-ECD method, and the effect of the background signal on PAN measurements is currently being discussed (Phillips et al., 2013). To evaluate the uncertainties further, direct comparisons of PAN flux measurements with the CIMS method and the GC-ECD HREA or MBR methods are desirable for future experiments.

\subsection{Sources of uncertainties of PAN mixing ratio differences}

As uncertainties in the PAN flux were mainly caused by random errors in the determination of $\Delta \chi_{\text {PAN }}$, we discuss potential error sources and possibilities for their reduction. Three different parts of the PAN measurement system contribute to the random errors: (a) the inlet tube; (b) the pre-concentration step; and (c) the peak separation, detection and integration. a. Uncertainties due to chemical reactions in the inlet tube could be excluded due the short sample air residence time of $\sim 1.5 \mathrm{~s}$ (HREA) and $\sim 3.0 \mathrm{~s}(\mathrm{MBR})$ and turbulent flow conditions. Experiments employing different inlet tube lengths revealed that the main effect of the sample tube was due to its impact on the pressure conditions in the PCUs, which was accounted for by using the same inlet tube length also during calibration (Sect. 2.6.1).

b. The use of capillary columns as a reservoir for the REA, MBR or other gradient methods is unique and required the application in conservation mode (Sect. 2.2). Since we determined the saturation point regularly and found a good linear relationship between the PAN mixing ratio and the ratio of peak integral and sampled volume, potential uncertainties associated with the preconcentration step are not caused by the operation in the conservation mode in general.

However, the higher random errors found during the side-by-side measurement in the HREA mode (Sect. 3.3) suggest that disturbed flow conditions due to fast switching may have an influence on the performance of the PCUs. Apparently, short-term pressure differences induced by the fast switching of the splitter valves or varying sample volumes influence the quality of the PAN measurement. As shown by the developed correction functions for the HREA fluxes (Sect. SM4 in the Supplement), we found that larger deviations were correlated with larger sample volume differences between both reservoirs. Large differences in the sample volume are caused by an imbalance of up- and downdraft events during the sampling interval. This is accompanied by an imbalance of the mean duration of up- and downdraft events, which might have an effect on the pressure equilibrium states in the PCUs. Although we did not observe any pressure change downstream of the PCUs induced by the switching of the splitter valves, it might be possible that very small pressure fluctuations inside the PCUs led to the higher random errors for the HREA operation. Hence, we suggest that future setups should employ capillary columns using zero air when one PCU is not active. However, in our case this would have increased the total sample time for each PCU from around $4 \mathrm{~min}$ (Sect. 3.2) to $30 \mathrm{~min}$ and required either a much lower sample flow or a longer capillary column to avoid breakthrough of the PAN frontal zone. Since a much lower sample flow than the one used here $\left(\sim 1 \mathrm{~mL} \mathrm{~min}^{-1}\right.$ ) would cause other problems and is not desired, more efforts should be made to develop PCUs with longer capillary columns. In this case, the quantitative release of all PAN from the column during injection is the major challenge. 
Since the pre-concentration efficiency is largely depend on the cooling temperature, small fluctuations of the pre-concentration temperature might also cause random errors. Due to the optimised temperature control of the PCUs, the cooling temperature, which was set to $-5^{\circ} \mathrm{C}$, showed variations of only $\pm 0.1 \mathrm{~K}$. Furthermore, temperature measurements at different parts of the capillary column revealed that potential temperature differences along the column were less than $0.5 \mathrm{~K}$. We found an increase of the pre-concentration efficiency of around $4 \% \mathrm{~K}^{-1}$ in the temperature range from +5 to $-5^{\circ} \mathrm{C}$. Consequently, larger variations of the cooling temperature would be necessary to have a noticeable effect on the precision of the PAN measurements. In addition, variations of the heating temperature during injection were also small compared to their potential effect. Nevertheless, it cannot be excluded that a significant improvement of the temperature control would reduce the uncertainties.

It was found that contamination of the pre-concentration capillary column was problematic. After some time of operation additional peaks in the chromatogram were observed when heating the pre-concentration capillary column above $50^{\circ} \mathrm{C}$ in the injection mode. Hence, we suggest either cleaning the column by regularly heating it or exchanging the pre-concentration column from time to time.

c. The chromatogram of the PAN GC featured a PAN peak directly preceded by a carbon tetrachloride $\left(\mathrm{CCl}_{4}\right)$ peak, which is present at a relatively constant level in the atmosphere (Galbally, 1976) and detected by the ECD due to its electron affinity. Although we achieved a good chromatographic resolution $(R \sim 1)$ with the employed operation settings, a small overlap of both peaks leads to potential errors that might be relevant when resolving small differences. We tested this effect by comparing the results from the integration using the ADAM32 software with another independent software program and found a random integration error of only $2 \%$.

Moreover, we found a temperature dependency of the PAN signal which could not be attributed to one single instrument part or process. For slow temperature changes with small diurnal amplitudes the PAN integrals were anti-correlated to the temperature measured inside the instrument, and a temperature change of $2 \mathrm{~K}$ led to a change of PAN integrals of approximately $5 \%$. During the field experiment the air conditioning controlled the air temperature in the measurement container to $\pm 1 \mathrm{~K}$ with an average periodicity of around $15 \mathrm{~min}$. Since the observed temperature effect was of inertial nature and a slow temperature change would have an effect on the measurement of the PAN from both PCUs, we found the impact of the temperature effect to be insignificant for our results. However, as the potential influence of fast temperature variations could not be determined and cannot be excluded, we suggest for future setups, aiming to resolve small mixing ratio differences, to place the GC in a thermally insulated and temperature-controlled compartment (Flocke et al., 2005). An effective method to adjust for instrumental variations and thereby reduce the uncertainties of the GC might be the addition of an internal standard to the main inlet line of the REA system (Schade and Goldstein, 2001; Park et al., 2010). Due to the small mass flow variations as a result of maintaining a constant lag time during the HREA application, the use of an internal standard was not feasible for the presented system.

\subsection{Scalar similarity and influence of chemistry}

Scalar similarity is defined as the similarity in the scalar time series throughout the scalar spectra (Kaimal et al., 1972; Pearson et al., 1998). Since the maximal time resolution of a single PAN measurement with the GC-ECD was $10 \mathrm{~min}$, we could not determine its scalar spectrum over the whole range to obtain a detailed analysis as suggested by other authors (Pearson et al., 1998; Ruppert et al., 2006). However, the distribution of sources and sinks within the footprint area is an important factor determining scalar similarity. The tropospheric production of $\mathrm{O}_{3}$ and PAN is strongly coupled to photochemistry and driven by the abundance of hydrocarbons (Roberts, 1990; Seinfeld and Pandis, 2006). Furthermore, for both quantities downward transport from higher altitudes is an important source to the lower boundary layer (Singh, 1987). The sink distribution of both $\mathrm{O}_{3}$ and PAN is strongly linked to dry deposition to the biosphere, in our case the grassland species at the Mainz-Finthen experimental site. Although we can assume that stomatal uptake is the major deposition process for both $\mathrm{O}_{3}$ (Zhang et al., 2006; Bassin et al., 2004; Coyle et al., 2009) and PAN (Sparks et al., 2003; Okano et al., 1990) when stomatal opening is not inhibited, the role of cuticular and mesophyllic uptake processes for PAN (Sparks et al., 2003; Doskey et al., 2004; Teklemariam and Sparks, 2004; Turnipseed et al., 2006) as well as deposition on soil are not well understood (see also Sect. 1), which may be the cause for some divergence from scalar similarity between $\mathrm{O}_{3}$ and PAN.

In order to investigate whether near-ground production, depletion or reaction with other species has an effect on the application of the HREA and MBR method, we analysed the ratio between chemical timescales for PAN (see Doskey et al., 2004) and turbulent transport times (see Stella et al., 2012 for calculation) in the respective layer (Damköhler number $(D a))$. For PAN, daytime $D a$ values were below $1.0 \times 10^{-2}$ and night-time values below $0.5 \times 10^{-2}$, revealing that chemical timescales were much longer than turbulent transport and, thus, did not have an effect on the flux measurements. This implies that the contribution of the thermochemical loss of PAN to the total flux, as e.g. observed by Wolfe et al. (2009), was negligible. Furthermore, reactions with volatile organic 
compounds are unlikely due to their very low abundance at the site (e.g. isoprene $<0.7 \mathrm{ppb}$, monoterpene $<0.3 \mathrm{ppb}$; J. Kesselmeier, personal communication, 2013).

For $\mathrm{O}_{3}$ a similar ratio between turbulent and chemical timescales was found $\left(D a<2.0 \times 10^{-2}\right)$, except between 06:00 and 10:00 CET, when higher NO mixing ratios led to a faster $\mathrm{O}_{3}$ depletion. During that time, $\mathrm{Da}$ values of up to 0.25 occurred occasionally (median: $<4.0 \times 10^{-2}$ ). Consequently, chemical reactions might have had an influence on $\mathrm{O}_{3}$ flux measurements during these periods.

\subsection{Applicability of HREA and MBR for PAN flux measurements}

As shown in the previous sections, the applicability of HREA and MBR for PAN flux measurements largely depends on the capability of the flux measurements system to resolve small PAN mixing ratios. Furthermore, the magnitude of the measured mixing ratio differences is influenced by the meteorological conditions, the PAN deposition as well as the dead band setting (HREA) and the separation of the inlets (MBR).

The simulation analysis revealed that expected daytime $\Delta \chi_{\text {PAN }}$ values were of similar magnitude for both the HREA and MBR method (Sect. 3.1.2, Fig. 4). Prior to the measurements it was assumed that, especially under conditions when strong turbulent mixing results in only small vertical mixing ratio gradients, the application of the REA method might be preferred. However, for the conditions at the Mainz-Finthen grassland site and for the presented setup of inlet heights (Sect. 2.1.2) and dead band settings (Sect. 3.1.1), no significant advantage of the HREA method was found. To evaluate the conditions under which the HREA method may be favoured over the MBR method (higher $\Delta \chi_{\text {PAN }}$ values) for the presented PAN flux measurements, we examine the ratio of the derived mixing ratio differences by the MBR and HREA method. Using the relationships in Eqs. (1) and (4), we obtain a description of this ratio, which is independent of the PAN flux:

$$
\frac{\Delta \chi_{\mathrm{PAN}}(\mathrm{MBR})}{\Delta \chi_{\mathrm{PAN}}(\mathrm{HREA})}=\frac{F_{\mathrm{PAN}}}{\left(-v_{\mathrm{tr}}\right)} \cdot \frac{b \cdot \sigma_{\mathrm{w}}}{F_{\mathrm{PAN}}} .
$$

Instead of determining $v_{\text {tr }}$ with a proxy scalar, its aerodynamic representation can be used (see Sect. 4.1.3). Expressing Eq. (10) for any scalar quantity and gradient measurements in general, the ratio of $\Delta \chi$ from gradient and REA measurements $\left(Q_{\Delta \chi}\right)$ is then represented by

$$
\begin{aligned}
Q_{\Delta \chi} & =\frac{\Delta \chi(\text { Gradient })}{\Delta \chi(\text { REA })}= \\
& \frac{b}{\kappa} \cdot \frac{\sigma_{\mathrm{w}}}{u_{*}} \cdot\left(\ln \frac{z_{2}}{z_{1}}-\Psi\left(\frac{z_{2}}{L}\right)+\Psi\left(\frac{z_{1}}{L}\right)\right),
\end{aligned}
$$

while $Q_{\Delta \chi}^{-1}$ is defined as the inverse of $Q_{\Delta \chi}$.

Since the $b$ value can be considered a constant for a certain dead band size (see Figs. 3 and 7e), $Q_{\Delta \chi}$ and $Q_{\Delta \chi}^{-1}$ are a function of the inlet heights of the gradient measurements, the stability correction function terms and $\frac{\sigma_{\mathrm{w}}}{u_{*}}$. The latter represents the integral turbulence characteristics for $w$, which can be parameterised as a function of $\frac{z}{L}$ (Panofsky et al., 1977). For the turbulence data at the Mainz-Finthen grassland site we found the best agreement using the parameterisation given by Panofsky et al. (1977) for $\frac{z}{L}<0$ :

$\frac{\sigma_{\mathrm{w}}}{u_{*}}=1.3 \cdot\left(1-2 \cdot \frac{z}{L}\right)^{1 / 3} ; \quad \frac{z}{L}<0$,

and for $\frac{z}{L} \geq 0$ a constant value independent from stability:

$\frac{\sigma_{\mathrm{w}}}{u_{*}}=1.3 ; \quad \frac{z}{L} \geq 0$.

Inserting the parameterisations in Eq. (11), we derive a func-

tion for $Q_{\Delta \chi}$ which is only dependent on the inlet heights of the gradient system, the REA dead band size and $\frac{z}{L}$. In case either $z_{1}$ or $z_{2}$ is used as the reference level for $\frac{z}{L}$, the stability correction term is independent from the absolute inlet heights and only their ratio $\left(m=z_{2} / z_{1}\right)$ has to be given. Figure 11 displays the expected $Q_{\Delta \chi}$ and $Q_{\Delta \chi}^{-1}$ values for $m=8$ and $m=1.5$, representing gradient measurements above low and high vegetation, respectively. For $m=8$ and $b=0.6$, we find, under unstable to near-neutral conditions, $Q_{\Delta \chi}$ ranging between 1.5 and 2; i.e. the gradient method yields higher $\Delta \chi$ values than the REA method. In contrast, when using a REA dead band resulting in a $b$ value of 0.2 , higher $\Delta \chi$ values are retrieved with the REA method $\left(Q_{\Delta \chi}^{-1}>1\right)$. For $m=1.5$, $Q_{\Delta \chi}^{-1}$ values are greater than 2,3 and 4 for $b$ values of $0.6,0.4$ and 0.2 , respectively. Hence, above high vegetation the REA method has a clear advantage under unstable and also neutral conditions. During stable conditions, the REA method only yields higher $\Delta \chi$ values when choosing a dead band above high vegetation. However, for most other settings, the ratio shows a steep linear increase from near-neutral to stable conditions in favour of the gradient method, obtaining higher $\Delta \chi$ values. Since the latter especially prevail under weak turbulence conditions, it has to be noted again that fluxes under stable conditions might still be prone to large errors when determined with the gradient method. Consequently, a turbulence criterion as for the MBR method (Sect. 2.1.2) should be applied.

Applying the setting used in this study $\left(m=\left(z_{2}-d\right) /\left(z_{1}-\right.\right.$ $d)=10$ and $b=0.21$ ), larger $\Delta \chi$ values are expected with the MBR method than with the HREA method not only for stable and neutral but also for unstable conditions (Fig. 11). During the latter, when highest PAN deposition fluxes are expected, $Q_{\Delta \chi}$ is nearly unity at $\frac{z}{L}=-1$, but increases to about 1.3 at the transition between unstable and neutral conditions. The curve representing this study is in good agreement with the ratios of $\Delta \chi$ obtained by the simulation analysis of MBR and HREA measurements (Sects. 2.7 and 3.1). This confirms that the presented method can be a simple tool to evaluate the 


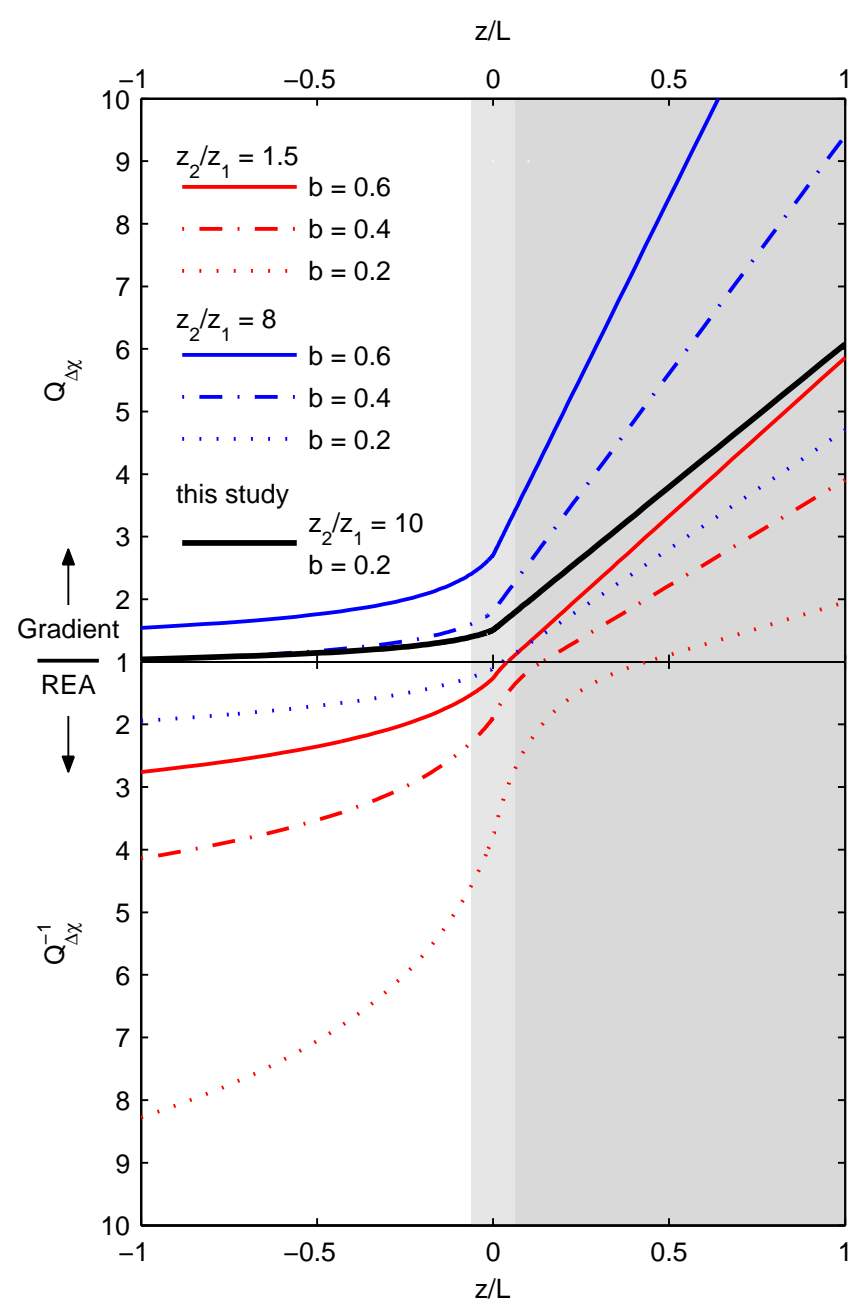

Figure 11. Expected $\Delta \chi$ (Gradient) $/ \Delta \chi(\mathrm{REA})$ ratio $\left(Q_{\Delta} \chi\right)$ displayed on the upper $y$ axis and the $\Delta \chi($ REA $) / \Delta \chi$ (Gradient) ratio, $\left(Q_{\Delta \chi}^{-1}\right)$ displayed on the lower $y$ axis (reversed) versus $\frac{z}{L}$. Shown are the ratios determined with Eq. (11) for $\mathrm{m}=\frac{z_{2}}{z_{1}}=8$ (blue lines) and $\mathrm{m}=\frac{z_{2}}{z_{1}}=1.5$ (red lines), representing gradient measurements above low and high vegetation, respectively, and $b$ values of 0.6 (solid line), 0.4 (dashed line) and 0.2 (dotted line). The black line was calculated with the settings from this study $(m=$ $\left(z_{2}-d\right) /\left(z_{1}-d\right)=10$ and $\left.b=0.21\right)$. The upper measurement height of the gradient measurement $\left(z_{2}\right)$ was used as a reference height for $\frac{z}{L}$ in Eq. (11) and in the calculation of the integral turbulence characteristics (Eq. 12). The shaded areas indicate ranges of unstable (white), neutral (light grey) and stable (dark grey) conditions. During the latter, fluxes might be prone to large errors when determined with the gradient method, and a turbulence criterion as for the MBR method (Sect. 2.1.2) should be applied.

applicability of the REA and gradient approach, especially when small mixing ratio differences are expected, as in our case for PAN.

\section{Summary and conclusions}

We developed a measurement system for the determination of biosphere-atmosphere exchange fluxes using both the HREA and MBR method. It is the first REA system for the determination of PAN fluxes, and the system was designed such that it could also be used for simultaneous measurements at two inlet heights for application of the gradient approach. Sampling for both methods was realised by trapping PAN onto two pre-concentration columns over a sampling period of $30 \mathrm{~min}$ and subsequent analysis by a GCECD. A linear relationship was found between the PAN peak area and both the PAN mixing ratio and the sample volume. This allowed the system to be used with varying sample volumes, which is a prerequisite for the application of the HREA method.

We validated the system and made PAN flux measurements at a natural grassland site at the estate of the MainzFinthen Airport, Rhineland-Palatinate, Germany. For the implementation of the HREA method the wind vector was adjusted online using the double rotation method. Highfrequency $\mathrm{O}_{3}$ measurements were used as a proxy for calculating the hyperbolic dead band $(H=1.1)$ and $b$ coefficient $(\sim 0.21)$. The application of the hyperbolic dead band reduced the sampling time to about $12 \%$ for each reservoir. The setup of the system allowed compensating the resulting reduction of the sample volume by a higher flow rate through the pre-concentration columns. The lag time between the vertical wind speed signal and the splitter valves - a crucial parameter to determine accurate fluxes - was determined continuously online during the measurements and varied by about $\pm 200 \mathrm{~ms}$, mainly depending on the prevailing wind direction and the error of the cross-correlation method. Highfrequency attenuation due to the long intake tube was found to be small and corrected for.

Flux simulations revealed that the uncertainties in measured mixing ratio differences are the most critical issue for a successful application of both the HREA and the MBR method. For the presented natural grassland site, the system should be able to resolve mixing ratio differences of at least $30 \mathrm{ppt}$ for both the MBR and the HREA method to obtain significant daytime fluxes of PAN. The precision of the gradient system was determined by side-by-side measurements and ranged from 4 to 15 ppt. During the HREA application the precision ranged between 18 and 26 ppt after applying a correction for pressure fluctuations. The higher noise in PAN mixing ratios during HREA application was most likely attributable to small pressure changes in the pre-concentration columns caused by the switching of the splitter valves.

We propagated the individual errors of the required quantities for the PAN flux determination and derived median random errors of the daytime PAN fluxes of $\pm 0.077 \mathrm{nmol} \mathrm{m}^{-2} \mathrm{~s}^{-1}$ for the HREA system and of $\pm 0.033 \mathrm{nmol} \mathrm{m}^{-2} \mathrm{~s}^{-1}$ for the MBR system. Most values were below the flux detection limit for the HREA 
measurements, which was attributed not only to the lower precision but also to the fact that the HREA measurement period took place in autumn (lower fluxes prevailed due to higher surface resistance) and weaker turbulence than during the MBR period. In contrast, significant PAN deposition fluxes could be resolved during the MBR measurement period in summer yielding mean daytime PAN deposition fluxes of $-0.07( \pm 0.06) \mathrm{nmol} \mathrm{m}^{-2} \mathrm{~s}^{-1}$, with maximal values reaching up to $-0.2 \mathrm{nmol} \mathrm{m}^{-2} \mathrm{~s}^{-1}$ during daytime. During night-time the fluxes were mostly close to zero or below the detection limit. The range of the obtained PAN differences matched the simulated differences well for both methods, which indicate the plausibility of the PAN fluxes determined by the new system. Damköhler numbers of $<0.02$ for most periods revealed that chemical divergence due to thermal decomposition of PAN had no impact on the obtained fluxes.

Our results show that mainly the precision of the mixing ratio measurement by the GC-ECD has to be improved further to reduce the flux uncertainties. Since the largest uncertainties are most likely attributable to the pre-concentration of PAN, the operation of the PCUs should be optimised by adding zero when one reservoir is not active.

In general, the uncertainties are also expected to decrease when the system is applied in ecosystems exposed to higher PAN fluxes (i.e. higher leaf area index and lower surface resistance or higher PAN mixing ratios downwind of urban areas and higher surface roughness) than at the nutrient-poor grassland site.

Finally, we developed a simple method to test the feasibility of the gradient and REA methods for compounds exhibiting small surface-atmosphere exchange fluxes for different meteorological conditions at ecosystems with low and high vegetation. In general, the HREA method is favoured over high vegetation, while the MBR is more feasible at low vegetation.

\section{The Supplement related to this article is available online at doi:10.5194/amt-7-2097-2014-supplement.}

Acknowledgements. This project was funded by the Max Planck Society. We thank M. Welling for helpful comments on the flux system design as well as J.-C. Mayer and D. Plake for the setup and operation of additional measurements at the field site. We are grateful to $\mathrm{H}$. Gross for the electrical installations at the field site and for logistical support. We thank R. Schmitt for discussions and comments on the modification of the PAN GC-ECD. We are also indebted to the staff of the MPIC mechanical and electronic workshop for their substantial support.

The service charges for this open access publication have been covered by the Max Planck Society.

Edited by: A. Hofzumahaus

\section{References}

Ammann, C. and Meixner, F. X.: Stability dependence of the relaxed eddy accumulation coefficient for various scalar quantities, J. Geophys. Res.-Atmos., 107, 4071, doi:10.1029/2001jd000649, 2002.

Baker, J. M.: Conditional sampling revisited, Meeting of the American-Society-of-Agronomy, Indianapolis, Indiana, 2000, ISI:000088180200006, 59-65, 2000.

Baker, J. M., Norman, J. M., and Bland, W. L.: Field-scale application of flux measurement by conditional sampling, Agr. Forest Meteorol., 62, 31-52, 1992.

Bassin, S., Calanca, P., Weidinger, T., Gerosa, G., and Fuhrer, E.: Modeling seasonal ozone fluxes to grassland and wheat: model improvement, testing, and application, Atmos. Environ., 38, 2349-2359, doi:10.1016/j.atmosenv.2003.11.044, 2004.

Beverland, I. J., Milne, R., Boissard, C., Oneill, D. H., Moncrieff, J. B., and Hewitt, C. N.: Measurement of carbon dioxide and hydrocarbon fluxes from a sitka spruce forest using micrometeorological techniques, J. Geophys. Res. Atmos., 101, 22807-22815, doi:10.1029/96jd01933, 1996.

Bowling, D. R., Delany, A. C., Turnipseed, A. A., Baldocchi, D. D., and Monson, R. K.: Modification of the relaxed eddy accumulation technique to maximize measured scalar mixing ratio differences in updrafts and downdrafts, J. Geophys. Res.-Atmos., 104, 9121-9133, 1999.

Businger, J. A.: Evaluation of the Accuracy with Which Dry Deposition Can Be Measured with Current Micrometeorological Techniques, J. Clim. Appl. Meteorol., 25, 1100-1124, doi:10.1175/1520-0450(1986)025<1100:Eotaww>2.0.Co;2, 1986.

Businger, J. A. and Oncley, S. P.: Flux Measurement with Conditional Sampling, J. Atmos. Ocean. Technol., 7, 349-352, 1990.

Businger, J. A., Wyngaard, J. C., Izumi, Y., and Bradley, E. F.: Flux-Profile Relationships in the Atmospheric Surface Layer, J. Atmos. Sci., 28, 181-189, doi:10.1175/15200469(1971)028<0181:fprita>2.0.co;2, 1971.

Cazorla, M. and Brune, W. H.: Measurement of Ozone Production Sensor, Atmos. Meas. Tech., 3, 545-555, doi:10.5194/amt3-545-2010, 2010.

Coyle, M., Nemitz, E., Storeton-West, R., Fowler, D., and Cape, J. N.: Measurements of ozone deposition to a potato canopy, Agr. Forest Meteorol., 149, 655-666, doi:10.1016/j.agrformet.2008.10.020, 2009.

Doskey, P. V., Kotamarthi, V. R., Fukui, Y., Cook, D. R., Breitbeil, F. W., and Wesely, M. L.: Air-surface exchange of peroxyacetyl nitrate at a grassland site, J. Geophys. Res.-Atmos., 109, D10310, 10.1029/2004jd004533, 2004.

Ermel, M., Oswald, R., Mayer, J. C., Moravek, A., Song, G., Beck, M., Meixner, F. X., and Trebs, I.: Preparation Methods to Optimize the Performance of Sensor Discs for Fast Chemiluminescence Ozone Analyzers, Environ. Sci. Technol., 47, 1930-1936, doi:10.1021/es3040363, 2013.

Fischer, E. V., Jaffe, D. A., and Weatherhead, E. C.: Free tropospheric peroxyacetyl nitrate (PAN) and ozone at Mount Bachelor: potential causes of variability and timescale for trend detection, Atmos. Chem. Phys., 11, 5641-5654, doi:10.5194/acp-115641-2011, 2011.

Flocke, F. M., Weinheimer, A. J., Swanson, A. L., Roberts, J. M., Schmitt, R., and Shertz, S.: On the measurement of PANs by 
gas chromatography and electron capture detection, J. Atmos. Chem., 52, 19-43, doi:10.1007/s10874-005-6772-0, 2005.

Foken, T.: Micrometeorology, Springer, Berlin, 306 pp., 2008.

Foken, T. and Wichura, B.: Tools for quality assessment of surfacebased flux measurements, Agr. Forest Meteorol., 78, 83-105, doi:10.1016/0168-1923(95)02248-1, 1996.

Foken, T., Dlugi, R., and Kramm, G.: On the determination of dry deposition and emission of gaseous compounds at the biosphereatmosphere interface, Meteorol. Z., 4, 91-118, 1995.

Foken, T., Göockede, M., Mauder, M., Mahrt, L., Amiro, B., and Munger, W.: Post-Field Data Quality Control, in: Handbook of Micrometeorology, edited by: Lee, X., Massman, W., and Law, B., Atmospheric and Oceanographic Sciences Library, Springer Netherlands, 181-208, 2004.

Galbally, I. E.: Man-Made Carbon-Tetrachloride in Atmosphere, Science, 193, 573-576, 1976.

Garland, J. A.: The dry deposition of sulphur dioxide to land and water surfaces, Proc. R. Soc. London Ser. A-Math. Phys. Eng. Sci., 354, 245-268, doi:10.1098/rspa.1977.0066, 1977.

Garland, J. A. and Penkett, S. A.: Absorption of peroxy acetyl nitrate and ozone by natural surfaces, Atmos. Environ., 10, 11271131, 1976.

Göckede, M., Rebmann, C., and Foken, T.: A combination of quality assessment tools for eddy covariance measurements with footprint modelling for the characterisation of complex sites, Agr. Forest Meteorol., 127, 175-188, doi:10.1016/j.agrformet.2004.07.012, 2004.

Göckede, M., Markkanen, T., Hasager, C. B., and Foken, T.: Update of a footprint-based approach for the characterisation of complex measurement sites, Bound.-Lay. Meteorol., 118, 635-655, doi:10.1007/s10546-005-6435-3, 2006.

Hicks, B. B., Baldocchi, D. D., Meyers, T. P., Hosker, R. P., and Matt, D. R.: A preliminary multiple resistance routine for deriving dry deposition velocities from measured quantities, Water Air Soil Poll., 36, 311-330, doi:10.1007/bf00229675, 1987.

Hill, A. C.: Vegetation - sink for atmospheric pollutants, J. Air Pollut. Cont. Assoc., 21, 341-346, 1971.

Högström, U.: Non-dimensional wind and temperature profiles in the atmospheric surface layer: A re-evaluation, Bound.-Lay. Meteorol., 42, 55-78, doi:10.1007/bf00119875, 1988.

Jacobi, H. W., Weller, R., Bluszcz, T., and Schrems, O.: Latitudinal distribution of peroxyacetyl nitrate (PAN) over the Atlantic Ocean, J. Geophys. Res.-Atmos., 104, 26901-26912, doi:10.1029/1999jd900462, 1999.

Kaimal, J. C., Izumi, Y., Wyngaard, J. C., and Cote, R.: Spectral characteristics of surface-layer turbulence, Q. J. R. Meteorol. Soc., 98, 563-589, doi:10.1002/qj.49709841707, 1972.

Liu, H. P. and Foken, T.: A modified Bowen ratio method to determine sensible and latent heat fluxes, Meteorol. Z., 10, 71-80, doi:10.1127/0941-2948/2001/0010-0071, 2001.

Magnani, F., Mencuccini, M., Borghetti, M., Berbigier, P., Berninger, F., Delzon, S., Grelle, A., Hari, P., Jarvis, P. G., Kolari, P., Kowalski, A. S., Lankreijer, H., Law, B. E., Lindroth, A., Loustau, D., Manca, G., Moncrieff, J. B., Rayment, M., Tedeschi, V., Valentini, R., and Grace, J.: The human footprint in the carbon cycle of temperate and boreal forests, Nature, 447, 848-850, doi:10.1038/nature05847, 2007.

Mauder M. and Foken T.: Documentation and instruction manual of the eddy covariance software package TK3, vol 46, Arbeit- sergebnisse, Universität Bayreuth, Abteilung Mikrometeorologie, 60 pp., ISSN 1614-8916, 2011.

Mauder, M., Cuntz, M., Drüe, C., Graf, A., Rebmann, C., Schmid, H. P., Schmidt, M., and Steinbrecher, R.: A strategy for quality and uncertainty assessment of long-term eddycovariance measurements, Agr. Forest Meteorol., 169, 122-135, doi:10.1016/j.agrformet.2012.09.006, 2013.

Mills, G. P., Sturges, W. T., Salmon, R. A., Bauguitte, S. J.-B., Read, K. A., and Bandy, B. J.: Seasonal variation of peroxyacetylnitrate (PAN) in coastal Antarctica measured with a new instrument for the detection of sub-part per trillion mixing ratios of PAN, Atmos. Chem. Phys., 7, 4589-4599, doi:10.5194/acp-7-4589-2007, 2007.

Moravek, A., Trebs, I., and Foken, T.: Effect of imprecise lag time and high-frequency attenuation on surface-atmosphere exchange fluxes determined with the relaxed eddy accumulation method, J. Geophys. Res. Atmos., 118, 10210-10224, doi:10.1002/jgrd.50763, 2013.

Neff, J. C., Holland, E. A., Dentener, F. J., McDowell, W. H., and Russell, K. M.: The origin, composition and rates of organic nitrogen deposition: A missing piece of the nitrogen cycle?, Biogeochemistry, 57, 99-136, 2002.

Novak, J., Janak, J., and Golias, J.: New concepts of quantification in headspace gas analysis by stripping and trapping components in a closed circuit, in Proceedings of the 9th Materials Research Symposium, 10-13 April 1978, held at NBS, Gaithersburg, MD, NBS Special Publication, No 519, National Bureau of Standards, Washington, DC, 739-746, 1979.

Okano, K., Tobe, K., and Furukawa, A.: Foliar Uptake of Peroxyacetyl Nitrate (PAN) by Herbaceous Species Varying in Susceptibility to this Pollutant, New Phytol., 114, 139-145, doi:10.1111/j.1469-8137.1990.tb00384.x, 1990.

Oncley, S. P., Delany, A. C., Horst, T. W., and Tans, P. P.: Verification of flux measurement using relaxed eddy accumulation, Atmos. Environ., 27, 2417-2426, 1993.

Panofsky, H. A., Tennekes, H., Lenschow, D. H., and Wyngaard, J. C.: The characteristics of turbulent velocity components in the surface layer under convective conditions, Bound.-Lay. Meteorol., 11, 355-361, doi:10.1007/bf02186086, 1977.

Park, C., Schade, G. W., and Boedeker, I.: Flux measurements of volatile organic compounds by the relaxed eddy accumulation method combined with a GC-FID system in urban Houston, Texas, Atmos. Environ., 44, 2605-2614, doi:10.1016/j.atmosenv.2010.04.016, 2010.

Pätz, H. W., Lerner, A., Houben, N., and Volz-Thomas, A.: Validation of a new method for the calibration of peroxy acetyl nitrate (PAN)-analyzers, Gefahrst. Reinhalt. Luft, 62, 215-219, 2002.

Pearson, R. J., Oncley, S. P., and Delany, A. C.: A scalar similarity study based on surface layer ozone measurements over cotton during the California Ozone Deposition Experiment, J. Geophys. Res. Atmos., 103, 18919-18926, 1998.

Phillips, G. J., Pouvesle, N., Thieser, J., Schuster, G., Axinte, R., Fischer, H., Williams, J., Lelieveld, J., and Crowley, J. N.: Peroxyacetyl nitrate (PAN) and peroxyacetic acid (PAA) measurements by iodide chemical ionisation mass spectrometry: first analysis of results in the boreal forest and implications for the measurement of PAN fluxes, Atmos. Chem. Phys., 13, 11291139, doi:10.5194/acp-13-1129-2013, 2013. 
Rannik, U., Aubinet, M., Kurbanmuradov, O., Sabelfeld, K. K., Markkanen, T., and Vesala, T.: Footprint analysis for measurements over a heterogeneous forest, Bound.-Lay. Meteorol., 97, 137-166, doi:10.1023/a:1002702810929, 2000.

Roberts, J. M.: The atmospheric chemistry of organic nitrates, Atmos. Environ., 24, 243-287, 1990.

Ruppert, J., Thomas, C., and Foken, T.: Scalar similarity for relaxed eddy accumulation methods, Bound.-Lay. Meteorol.y, 120, 3963, doi:10.1007/s10546-005-9043-3, 2006.

Schade, G. W. and Goldstein, A. H.: Fluxes of oxygenated volatile organic compounds from a ponderosa pine plantation, J. Geophys. Res.-Atmos., 106, 3111-3123, 2001.

Schrimpf, W., Muller, K. P., Johnen, F. J., Lienaerts, K., and Rudolph, J.: An Optimized Method for Airborne Peroxyacetyl Nitrate (Pan) Measurements, J. Atmos. Chem., 22, 303-317, doi:10.1007/Bf00696640, 1995.

Schrimpf, W., Lienaerts, K., Muller, K. P., Rudolph, J., Neubert, R., Schussler, W., and Levin, I.: Dry deposition of peroxyacetyl nitrate (PAN): Determination of its deposition velocity at night from measurements of the atmospheric PAN and (222)Radon concentration gradient, Geophys. Res. Lett., 23, 3599-3602, 1996.

Seinfeld, J. H. and Pandis, S. N.: Atmospheric chemistry and physics: from air pollution to climate change, Wiley, 2006.

Shepson, P. B., Bottenheim, J. W., Hastie, D. R., and Venkatram, A.: Determination of the relative ozone and PAN deposition velocities at night, Geophys. Res. Lett., 19, 1121-1124, 1992.

Singh, H. B.: Reactive Nitrogen in the Troposphere, Environ. Sci. Technol., 21, 320-327, doi:10.1021/Es00158a001, 1987.

Singh, H. B. and Hanst, P. L.: Peroxyacetyl nitrate (PAN) in the unpolluted atmosphere: An important reservoir for nitrogen oxides, Geophys. Res. Lett., 8, 941-944, doi:10.1029/GL008i008p00941, 1981.

Sparks, J. P., Roberts, J. M., and Monson, R. K.: The uptake of gaseous organic nitrogen by leaves: A significant global nitrogen transfer process, Geophys. Res. Lett., 30, 2189, doi:10.1029/2003g1018578, 2003.

Stella, P., Loubet, B., Laville, P., Lamaud, E., Cazaunau, M., Laufs, S., Bernard, F., Grosselin, B., Mascher, N., Kurtenbach, R., Mellouki, A., Kleffmann, J., and Cellier, P.: Comparison of methods for the determination of $\mathrm{NO}-\mathrm{O}_{3}-\mathrm{NO}_{2}$ fluxes and chemical interactions over a bare soil, Atmos. Meas. Tech., 5, 1241-1257, doi:10.5194/amt-5-1241-2012, 2012.

Stephens, E. R.: The formation reactions and properties of peroxyacyl nitrates in photochemical air pollution, edited by: Pitts, J. N. Jr. and Metcalf, R. L., 119-146, 1969.
Teklemariam, T. A. and Sparks, J. P.: Gaseous fluxes of peroxyacetyl nitrate (PAN) into plant leaves, Plant Cell Environ., 27, 1149-1158, 2004.

Turnipseed, A. A., Huey, L. G., Nemitz, E., Stickel, R., Higgs, J., Tanner, D. J., Slusher, D. L., Sparks, J. P., Flocke, F., and Guenther, A.: Eddy covariance fluxes of peroxyacetyl nitrates (PANs) and $\mathrm{NO}_{y}$ to a coniferous forest, J. Geophys. Res. Atmos., 111, D09304, doi:10.1029/2005jd006631, 2006.

Volz-Thomas, A., Xueref, I., and Schmitt, R.: An automatic gas chromatograph and calibration system for ambient measurements of PAN and PPN, Environ. Sci. Pollut. Res., 4, 72-76, 2002.

Wesely, M. L. and Hicks, B. B.: A review of the current status of knowledge on dry deposition, Atmos. Environ., 34, 2261-2282, doi:10.1016/s1352-2310(99)00467-7, 2000.

Williams, J., Roberts, J. M., Bertman, S. B., Stroud, C. A., Fehsenfeld, F. C., Baumann, K., Buhr, M. P., Knapp, K., Murphy, P. C., Nowick, M., and Williams, E. J.: A method for the airborne measurement of PAN, PPN, and MPAN, J. Geophys. Res.-Atmos., 105, 28943-28960, doi:10.1029/2000jd900373, 2000.

Wolfe, G. M., Thornton, J. A., Yatavelli, R. L. N., McKay, M., Goldstein, A. H., LaFranchi, B., Min, K.-E., and Cohen, R. C.: Eddy covariance fluxes of acyl peroxy nitrates (PAN, PPN and MPAN) above a Ponderosa pine forest, Atmos. Chem. Phys., 9, 615-634, doi:10.5194/acp-9-615-2009, 2009.

Wolff, V., Trebs, I., Ammann, C., and Meixner, F. X.: Aerodynamic gradient measurements of the $\mathrm{NH}_{3}-\mathrm{HNO}_{3}-\mathrm{NH}_{4} \mathrm{NO}_{3}$ triad using a wet chemical instrument: an analysis of precision requirements and flux errors, Atmos. Meas. Tech., 3, 187-208, doi:10.5194/amt-3-187-2010, 2010.

Wyngaard, J. C. and Moeng, C. H.: Parameterizing turbulent diffusion through the joint probability density, Bound.-Lay. Meteorol., 60, 1-13, 1992.

Zhang, G., Mu, Y. J., Liu, J. F., and Mellouki, A.: Direct and simultaneous determination of trace-level carbon tetrachloride, peroxyacetyl nitrate, and peroxypropionyl nitrate using gas chromatography-electron capture detection, J. Chromatogr. A, 1266, 110-115, doi:10.1016/j.chroma.2012.09.092, 2012.

Zhang, J. M., Wang, T., Ding, A. J., Zhou, X. H., Xue, L. K., Poon, C. N., Wu, W. S., Gao, J., Zuo, H. C., Chen, J. M., Zhang, X. C., and Fan, S. J.: Continuous measurement of peroxyacetyl nitrate (PAN) in suburban and remote areas of western China, Atmos. Environ., 43, 228-237, 2009.

Zhang, L. M., Vet, R., Brook, J. R., and Legge, A. H.: Factors affecting stomatal uptake of ozone by different canopies and a comparison between dose and exposure, Sci. Total Environ., 370, 117 132, doi:10.1016/j.scitotenv.2006.06.004, 2006. 